\title{
Floristic study of Mt. Baekasan
}

\section{Eun-Mi Sun, Byeol-Ah Kim ${ }^{1}$, Hyun-Deok Son ${ }^{2}$, Jeong-Chae Jeong ${ }^{3}$ and Hyoung-Tak $\mathrm{Im}^{4 *}$}

\author{
Forest Biodiversity Division Korea National Arboretum, Pocheon 11186, Korea \\ ${ }^{1}$ National Forest Seed Variety Center, Chungju 27495, Korea \\ ${ }^{2}$ Mokpo Natural History Museum, Mokpo 58699, Korea \\ ${ }^{3}$ Gwangju Dongsung High School, Gwangju 61737, Korea \\ ${ }^{4}$ Chonnam National University, Gwangju 61186, Korea
}

(Received 24 July 2017; Revised 30 August 2017; Accepted 18 September 2017)

\author{
백아산의 식물상 \\ 선은미 · 김별아 ${ }^{1} \cdot$ 손현덕 ${ }^{2} \cdot$ 정정채 $^{3} \cdot$ 임형탁 $^{4 *}$ \\ 국립수목원 산림생물조사과, ${ }^{1}$ 국립품종관리센터, ${ }^{2}$ 목포자연사박물관, ${ }^{3}$ 광주동성고등학교, ${ }^{4}$ 전남대학교
}

\begin{abstract}
This study presents a discussion of vascular plants found on Mt. Baekasan, Hwasun-gun, Jeollanam-do, based on specimens collected during 32 separate field trips amounting to a total of 36 days conducted between May of 2011 and October of 2016. There are 651 taxa on Mt. Baekasan, consisting of 109 families, 366 genera, 576 species, 5 subspecies, and 70 varieties. Twelve plants endemic to Korea were found, including Cirsium setidens (Dunn) Nakai and Scutellaria insignis Nakai. There are a total of 61 taxa of floristic regional indicator plants specially designated by the Ministry of the Environment. Rare plants such as Jeffersonia dubia (Maxim.) Benth. \& Hook. ex Baker \& S. Moore in Mt. Baekasan are 17 taxa in total, and red list plants number 8 taxa, including Cremastra variabilis (Blume) Nakai ex Shibata. Nine calciferous plants were found, including Asplenium ruprechtii Sa. Kurata, Ulmus davidiana var. japonica (Rehder) Nakai and Morus cathayana Hemsl. Thirty-three naturalized plants were also found, including Ambrosia artemisiifolia and Rumex acetosella.
\end{abstract}

Keywords: Mt. Baekasan, flora, floristic regional indicator plants, endemic plants, naturalized plants

적 요: 전라남도 화순군 북면에 위치하는 백아산의 관속식물상을 조사하고 분포가 확인된 주요식물에 대해 논의하였다. 2011년 5월부터 2016년 10월까지 6년 동안 총 32회(36일)의 현지조사에서 확보된 표본과 전남 대 생물학과 표본실 $(\mathrm{CNU})$ 의 수장표본에 근거하여 관속식물목록을 작성하였다. 조사된 관속식물은 109 과 366 속 576 종 5 아종 70 변종으로 총 651 분류군이다. 한국특산식물로는 고려엉겅퀴, 광릉골무꽃등 12 분류군을 확인하였다. 식물구계학적 특정식물로는 $\mathrm{V}$ 등급 2 분류군, IV등급 5 분류군, III등급 11 분류군, II등급 14 분류군, I등급 29분류군으로 총 61 분류군이 조사되었다. 희귀식물은 위기종(endangered species)인 깽깽이풀을 포함하 여 총 17 분류군을 확인하였고, 적색식물목록종으로는 약난초 등 총 8 분류군이 조사되었다. 호석회식물로는 거미고사리, 느릅나무, 돌뽕나무 등 9 분류군을 확인하였다. 귀화식물로는 돼지풀, 애기수영 등 33 분류군이 조사되었다.

주요어: 백아산, 식물상, 식물구계학적특정식물, 특산식물, 귀화식물

*Author for correspondence: ihtplant@hanmail.net 
백아산은 $35^{\circ} 10^{\prime} \mathrm{N}, 127^{\circ} 10^{\prime} \mathrm{E}$ 에 위치하는 해발 $817 \mathrm{~m}$ 의 산 으로, 행정구역상으로는 전라남도 화순군 북면에 속한다. 백아산은 식물지리학적으로 전라남도의 주된 산계인 지 리산과 무등산을 잇는 중요한 위치에 있고, 정상부근 능 선부에 석회석 노두가 있으며, 내복천에 인접한 남쪽 사 면에 전남지역의 유일한 석회동굴인 화순백아산자연동 굴(전라남도기념물 제 24호)이 발달되어 있다. 전체적으 로 사면 중부 이하에는 소나무림 또는 소나무-참나무림이
대부분이지만 일부 계곡의 급사면지에는 잘 발달된 낙엽 활엽수림이 보존되어 있으며, 낙엽활엽수림의 상층부는 참나무, 개암나무, 느티나무, 단풍나무, 층층나무, 때죽나 무, 물푸레나무 등으로 구성되어 있다. 백아산의 산림식 물대는 남부아구에 속하며(Lee and Lim, 1978), 온도 분포 에 의한 구분으로 난온대와 냉온대의 경계에 위치하는 온 대 하부에 해당한다.

백아산은 산체가 작아서 접근하기 쉬운 편이지만 기암

Table 1. Investigation dates and routes of the floristic study of Mt. Baeka in Korea.

\begin{tabular}{|c|c|}
\hline Date & Investigation routes \\
\hline May 7, 2011 & Nogijae (reservoir) $\rightarrow$ Mt. Baekasan $\rightarrow$ Nogijae (reservoir) \\
\hline May 67, 2012 & Songdan $\rightarrow$ Mt. Baekeasan $\rightarrow$ Gangrye \\
\hline May 13, 2012 & Nogijae (reservoir) $\rightarrow$ Mt. Baekasan $\rightarrow$ Nogijae (reservoir) \\
\hline Aug 12, 2012 & North slope of Mt. Baekasan \\
\hline Sep 14, 2012 & Gangrye $\rightarrow$ Mt. Baekasan $\rightarrow$ Gangrye \\
\hline Oct 5,2012 & Nogiri $\rightarrow$ Mt. Baekasan $\rightarrow$ Nogiri \\
\hline Apr 3, 2013 & Nogiri $\rightarrow$ Mt. Baekasan $\rightarrow$ Nogiri \\
\hline Apr 24, 2013 & Songdan $\rightarrow$ Mt. Baekasan $\rightarrow$ Songdan \\
\hline Jun 9,2013 & Songdanjae (reservoir) $\rightarrow$ Mt. Baekasan $\rightarrow$ Gangrye \\
\hline Jun 12,2013 & Yonggokri $\rightarrow$ Mt. Baekasan $\rightarrow$ Yonggokri \\
\hline Jul 23, 2013 & Songdan $\rightarrow$ Mt. Baekasan $\rightarrow$ Nogijae (reservoir) \\
\hline Aug 9, 2013 & Nogiri $\rightarrow$ Mt. Baekasan $\rightarrow$ Nogiri \\
\hline Sep 2, 2013 & Nogijae (reservoir) $\rightarrow$ Mt. Baekasan $\rightarrow$ Nogijae (reservoir) \\
\hline Sep 12, 2013 & Songdan $\rightarrow$ Mt. Baekasan $\rightarrow$ Songdan \\
\hline Sep 27, 2013 & Steep slope nearby Suri limestone cave \\
\hline Sep 30, 2013 & Songdanjae (reservoir) $\rightarrow$ Eastern valley of Mt. Baekasan \\
\hline Oct 12, 2013 & Yonggokjae (reservoir) $\rightarrow$ Mt. Baeka $\rightarrow$ Recreational forest of Mt. Baekasan \\
\hline Oct 1213,2013 & Yonggokri limestone quarry $\rightarrow$ Mt. Baekasan $\rightarrow$ Songdan \\
\hline Mar 24, 2014. & Nogiri $\rightarrow$ Mt. Baekasan $\rightarrow$ Nogiri \\
\hline Apr 4, 2014 & Songdan $\rightarrow$ Gangrye $\rightarrow$ Mt. Baekasan $\rightarrow$ Songdan \\
\hline May 10, 2014 & Nogiri $\rightarrow$ Mt. Baekasan $\rightarrow$ Nogiri \\
\hline May 24, 2014 & Bukmyeon $\rightarrow$ Mt. Baekasan $\rightarrow$ Bukmyeon \\
\hline May 31, 2014 & Songdan $\rightarrow$ Mt. Baekasan $\rightarrow$ Songdan \\
\hline Jun 12,2014 & Yonggokri limestone quarry \\
\hline Jul 6, 2014 & Nochiri $\rightarrow$ Mt. Baekasan $\rightarrow$ Nochiri \\
\hline Sep 19, 2014 & Nogiri $\rightarrow$ Mt. Baekasan $\rightarrow$ Nogiri \\
\hline Oct 12, 2014 & Yonggokri limestone quarry $\rightarrow$ Recreational forest of Mt. Baekasan $\rightarrow$ Mt. Baekasan $\rightarrow$ Nochiri \\
\hline Apr 22, 2015 & Nogijae (reservoir) $\rightarrow$ Mt. Baekasan $\rightarrow$ Nogijae (reservoir) \\
\hline Jun 22,2015 & Nochiri $\rightarrow$ East ridge of Mt. Baekasan $\rightarrow$ Songdan \\
\hline Oct 9, 2015 & Songdan $\rightarrow$ Mt. Baekasan $\rightarrow$ Songdan \\
\hline Jun 29, 2016 & Nogijae (reservoir) $\rightarrow$ Mt. Baekasan $\rightarrow$ Nogijae (reservoir) \\
\hline Oct 13, 2016 & Songdan $\rightarrow$ Mt. Baekasan $\rightarrow$ Songdan \\
\hline
\end{tabular}



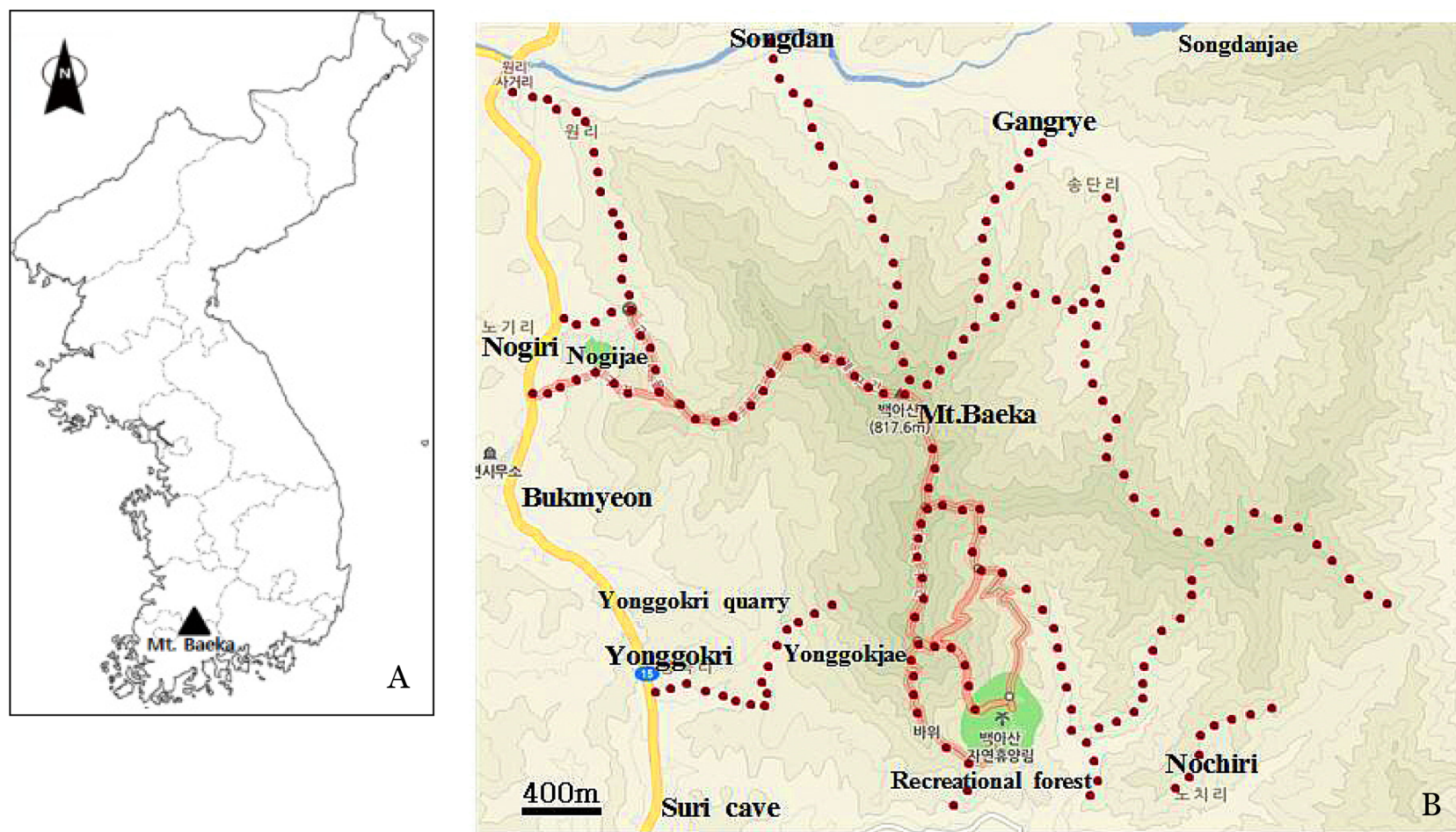

Fig. 1. Map of investigation area (A) and routes (B).

괴석이 많고 지형이 험한 곳은 울창한 숲이 남아 있다. 백 아산의 남서쪽을 중심으로 $100 \mathrm{ha}$ 에 이르는 백아산 자연 휴양림이 조성되어 있고 서쪽으로는 화순 금호리조트가 있어서 전남 중부 내륙의 유명 관광지 중 하나이다. 이러 한 이유로 인위적 간섭에 의한 자연환경 훼손은 날로 심 각해지고 있다. 또한 백아산의 석회암은 시멘트 원료로 산업적으로 채굴되어(Kim, 2003), 그 결과 $350 \mathrm{~m}$ 의 산봉우 리 하나가 완전히 파괴되기도 하였다. 백아산 식물상에 대한 기존의 연구는 없으나, 환경부 전국자연환경조사의 화순, 곡성지역 식물상의 일부로 백아산 식물상이 보고된 바 있다(Park and Kim, 2005). 본 연구는 백아산의 식물상 을 밝히고 그 식물지리학적 중요성을 논하는 데에 그 목 적이 있다.

\section{재료 및 방법}

현지조사는 2011년 5월부터 2016년 10월까지 6년 동안 총 32회(36일)에 걸쳐 이루어졌다(Table 1). 조사범위는 화 순군 북면 원리에서 시작하여 능선을 중심으로 북면 송단, 수리 지역에 이르고 조사경로는 Fig. 1과 같다. 조사 중에 확인된 모든 출현종을 채집하여 흡습지와 건조기를 이용 하여 건조시켰으며, 확증표본은 전남대학교 생물학과 표 본실(CNU)에 보관하였다. 식물목록 작성에 있어서 오랜 기간 널리 식재되어 온 식물 또는 자생하게 된 식물 이외
의 재배식물은 제외시켰다. 과별 배열은 한반도 속식물지 (Park, 2007)를 따랐고, 과 내에서는 알파벳 순서로 속명과 종명을 정리하였다. 학명은 국가표준식물목록(Korea National Arboretum and The Plant Taxonomic Society of Korea, 2007)을 따랐으며 작성된 식물목록을 한국특산식 물목록(Korea Forest Service, 2015), 희귀식물목록(Korea Forest Service, 2015), 적색목록(National Institute of Biological Resources, 2012), 식물구계학적 특정식물목록 (Ministry of Environment and National Institute of Environmental Research, 2014)에 근거하여 분석하였다. 한 국 내 귀화식물의 현황(Lee et al., 2011) 및 귀화식물목록 (Park, 1995)을 참고하여 귀화식물 목록을 작성하였다.

\section{결 과}

백아산 지역에서는 109 과 366 속 568 종 5 아종 69 변종 9 품종으로 총 651분류군이 확인되었다(Table 2, Appendix 1). 이는 한반도 관속식물 4,071 분류군(Lee, 1996)의 $16 \%$ 에 해당되며, 이 중 양치식물은 15 과 25 속 47 종 3 변종의 총 50 분류군 $(7.7 \%)$, 나자식물은 3 과 6 속 7 종의 총 7 분류군 (1.1\%)으로 나타났다. 피자식물 중 쌍자엽식물은 81 과 265 속 401종 5아종 51변종 9품종의 총 466분류군(71.6\%), 단 자엽식물은 10 과 70 속 113 종 15 변종의 총 128 분류군 $(19.7 \%)$ 이다. 
Table 2. The number of vascular plants in Mt. Baeka.

\begin{tabular}{ccccccc}
\hline \hline Taxa & \multicolumn{7}{c}{ Family } & Genus & Species Subspecies Variety & Form \\
\hline Pteriodophyta & 15 & 25 & 47 & - & 3 & - \\
Gymnospermae & 3 & 6 & 7 & - & - & - \\
Angiospermae & 91 & 335 & 514 & 5 & 66 & 9 \\
Dicotyledonae & 81 & 265 & 401 & 5 & 51 & 9 \\
Monocotyledonae & 10 & 70 & 113 & - & 15 & - \\
Total & 109 & 366 & 568 & 5 & 69 & 9 \\
\hline
\end{tabular}

\section{특산식물}

본 조사지역에서 확인된 651 분류군 중 특산식물은 고려 엉겅퀴(Cirsium setidens), 벌개미취(Aster koraiensis), 자란초 (Ajuga spectabilis), 광릉골무꽃(Scutellaria insignis, Fig. 2B), 외 대으아리(Clematis brachyura), 할미밀망(Clematis trichotoma), 병꽃나무(Weigela subsessilis), 지리대사초(Carex okamotoi), 매미꽃(Coreanomecon hylomeconoides), 노각나무(Stewartia pseudocamellia), 은사시나무(Populus tomentiglandulosa), 나래 완두(Vicia hirticalycina)로 총 9과 12속 12분류군이다(Table 3). 조사된 12 분류군은 우리나라 특산식물 328 분류군(Korea Forest Service, 2015)의 3.7\%에 해당된다.

\section{식물구계학적 특정식물}

식물구계학적 특정식물종은 총 61 분류군으로 백아산 에서 확인된 전체 651 분류군의 $9.2 \%$ 에 해당하며(Table 4), 환경부에 의해 지정된 식물구계학적 특정식물 1,257 분류 군(Ministry of Environment, 2014)의 4.9\%에 해당한다. V등

Table 3. The list of endemic plants to Korea in Mt. Baekasan.

\begin{tabular}{|c|c|}
\hline Family & Taxa \\
\hline Compositae 국화과 & $\begin{array}{l}\text { Cirsium setidens (Dunn) Nakai } \\
\text { 고려엉겅퀴 } \\
\text { Aster koraiensis Nakai 벌개미취 }\end{array}$ \\
\hline Labiatae 꿀풀과 & $\begin{array}{l}\text { Ajuga spectabilis Nakai 자란초 } \\
\text { Scutellaria insignis Nakai 광릉골무꽃 }\end{array}$ \\
\hline $\begin{array}{l}\text { Ranunculaceae 미나리아 } \\
\text { 재비과 }\end{array}$ & $\begin{array}{l}\text { Clematis brachyura Maxim 외대으아리 } \\
\text { Clematis trichotoma Nakai 할미밀망 }\end{array}$ \\
\hline Caprifoliaceae 인동과 & $\begin{array}{l}\text { Weigela subsessilis (Nakai) L. H. Bailey } \\
\text { 병꽃나무 }\end{array}$ \\
\hline Cyperaceae 사초과 & Carex okamotoi Ohwi 지리대사초 \\
\hline Papaveraceae 양귀비과 & $\begin{array}{l}\text { Coreanomecon hylomeconoides Nakai } \\
\text { 매미꽃 }\end{array}$ \\
\hline Theaceae 차나무과 & $\begin{array}{l}\text { Stewartia pseudocamellia Maxim. } \\
\text { 노각나무 }\end{array}$ \\
\hline Salicaceae 버드나무과 & $\begin{array}{l}\text { Populus tomentiglandulosa T. B. Lee } \\
\text { 은사시나무 }\end{array}$ \\
\hline Leguminosae 콩과 & Vicia hirticalycina Nakai 나래완두 \\
\hline
\end{tabular}

급종은 구슬개고사리(Athyrium deltoidofrons), 깽깽이풀 (Jeffersonia dubia) 2분류군, IV등급종은 산꽃고사리삼 (Sceptridium japonicum), 섬잔고사리(Diplazium hachijoense), 털조장나무(Lindera sericea), 매미꽃(Fig. 2F), 갈사초(Carex ligulata)등 5분류군, III등급종은 금족제비고사리(Dryopteris gymnophylla), 세뿔석위(Pyrrosia hastata), 난쟁이바위솔(Fig. $2 \mathrm{E}$ )등 11 분류군, II등급종은 뀡의다리아재비(Caulophyllum robustum)등 14 분류군이었으며, I등급종은 대팻집나무 (Ilex macropoda), 나도물통이(Nanocnide japonica)를 비롯 한 29분류군으로 확인되었다. 깽깽이풀은 개화시기에 남 획이 극심한 식물로 자생지에서 급격하게 소멸되고 있어 철저한 자생지 보존은 물론 자생지 외 보존을 실시해야만 하는 식물이다. 주 분포지는 아무르, 만주에서 경기 이북 에 이르지만, 전국 심산에 드물게 자란다. 전남에서는 지 리산, 조계산, 무등산에 알려져 있고(Park, 1970; Oh et al., 2016), 백아산에는 마당바위 북서사면의 등산로 주변에서 30 여 개체가 집단으로 자생하고 있다. 마당바위에 인접한 북서사면 상부 임상은 습윤하고 토심이 깊어서 구슬개고 사리, 약난초(Cremastra variabilis)와 같은 중요한 임상식 물을 볼 수 있는 백아산 식물상의 핵심지역에 해당한다. 세뿔석위는 태안반도에서 충무에 이르는 서남해안 지방 과 제주도에 주로 분포하는데, 백아산의 경우 마당바위에 서 하늘다리 사이의 석회암 노두에 자란다. 산꽃고사리삼 은 제주도와 전남 도서지방에 자라며, 내복천에 면한 백 아산 남사면 하부에 있는 석회동굴 주변 임상에서 확인되 었다. 갈사초와 금족제비고사리는 북면 노기리의 백아산 눈썰매장에 면한 사면 하부 $(350 \mathrm{~m})$ 의 임연부에 몇 개체 확

Table 4. The list of floristic regional indicator plants specially designated by the Ministry of Environment.

\begin{tabular}{cl}
\hline \hline Category & \multicolumn{1}{c}{ Taxa } \\
\hline $\mathrm{V} \quad \begin{array}{l}\text { Athyrium deltoidofrons Makino 구슬개고사리 } \\
\text { Jeffersonia dubia (Maxim.) Benth. \& Hook. ex. Baker \& }\end{array}$ \\
S. Moore 깽깽이풀 \\
IV $\quad$ Sceptridium japonicum (Prantl.) Lyon 산꽃고사리삼 \\
Diplazium hachijoense Nakai 섬잔고사리 \\
Lindera sericea (Siebold \& Zucc.) Blume 털조장나무 \\
Coreanomecon hylomeconoides Nakai 매미꽃 \\
Carex ligulata Nees 갈사초 \\
III \\
Dryopteris gymnophylla (Baker) C. Chr. 금족제비고사리 \\
Pyrrosia hastata (Thunb.) Ching 세뿔석위 \\
Stewartia pseudocamellia Maxim. 노각나무 \\
Idesia polycarpa Maxim. 이나무 \\
Philadelphus pekinensis Rupr. 애기고광나무 \\
Meterostachys sikokianus (Makino) Nakai 난쟁이바위솔 \\
Indigofera pseudotinctoria Matsum. 낭아초 \\
Scopolia japonica Maxim. 미치광이풀 \\
Scutellaria insignis Nakai 광릉골무꽃 \\
Carex gifuensis Franch. 애기감둥사초 \\
Cremastra variabilis (Blume) Nakai ex Shibata 약난초 \\
\hline
\end{tabular}


Table 4. Continued.

\begin{tabular}{|c|c|}
\hline Category & Taxa \\
\hline (1) & $\begin{array}{l}\text { Caulophyllum robustum Maxim. 꿩의다리아재비 } \\
\text { Morus cathayana Hemsl. 돌뽕나무 } \\
\text { Potentilla dickinsii Franch. \& Sav. 돌양지꽃 } \\
\text { Ajuga spectabilis Nakai 자란초 } \\
\text { Chionanthus retusus Ldl. \& Paxton 이팝나무 } \\
\text { Patrinia saniculifolia Hemsl. 금마타리 } \\
\text { Achillea alpina L. 톱풀 } \\
\text { Cirsium setidens (Dunn) Nakai 고려엉겅퀴 } \\
\text { Ligularia fischeri (Ledeb.) Turcz. 곰취 } \\
\text { Arisaema heterophyllum Blume 두루미천남성 } \\
\text { Carex okamotoi Ohwi 지리대사초 } \\
\text { C. pediformis C. A. Mey. 넓은잎그늘사초 } \\
\text { Iris ensata var. spontanea (Makino) Nakai 꽃창포 } \\
\text { Cephalanthera falcata (Thunb.) Blume 금난초 }\end{array}$ \\
\hline (1) & $\begin{array}{l}\text { Coniogramme japonica (Thunb.) Diels 가지고비고사리 } \\
\text { Thelypteris glanduligera (Kunze) Ching 사다리고사리 } \\
\text { Cyrtomium fortunei J. Sm. 쇠고비 } \\
\text { Dryopteris crassirhizoma Nakai 관중 } \\
\text { D. erythrosora (D.C. Eaton)Kuntze 홍지네고사리 } \\
\text { D. uniformis (Makino) Makino 곰비늘고사리 } \\
\text { Cephalotaxus koreana Nakai 개비자나무 } \\
\text { Chloranthus fortunei (A. Gray) Solms 옥녀꽃대 } \\
\text { Aristolochia contorta Bunge 쥐방울덩굴 } \\
\text { Aconitum jaluense Kom. 투구꽃 } \\
\text { Clematis patens C. Morren \& Decne. 큰꽃으아리 } \\
\text { Semiaquilegia adoxoides (DC.) Makino 개구리발톱 } \\
\text { Nanocnide japonica Blume 나도물통이 } \\
\text { Bistorta manshuriensis (Petrov ex Kom.) Kom. 범꼬리 } \\
\text { Grewia parviflora Bung 장구밤나무 } \\
\text { Gynostemma pentaphylla (Thunb.) Makino 돌외 } \\
\text { Vaccinium oldhamii Miq. 정금나무 } \\
\text { Hylotelephium verticillatum (L.) H. Ohba 세잎꿩의비름 } \\
\text { Potentilla cryptotaeniae Nakai 물양지꽃 } \\
\text { Vicia pseudorobus Fisch. \& C. A. Mey. 큰등갈퀴 } \\
\text { Ilex macropoda Miq. 대팻집나무 } \\
\text { Orixa japonica Thunb. 상산 } \\
\text { Oxalis obtriangulata Maxim. 큰괭이밥 } \\
\text { Clinopodium micranthum (Regel) Hara 두메층층이 } \\
\text { Ligustrum japonicum Thunb. 광나무 } \\
\text { Lonicera praeflorens Batalin 올괴불나무 } \\
\text { Carex nervata Franch. \& Sav. 양지사초 } \\
\text { Erythronium japonicum (Balrer) Decne. 얼레지 } \\
\text { Hosta capitata (Koidz.) Nakai 일월비비추 }\end{array}$ \\
\hline
\end{tabular}

인되었다. 미치광이풀(Scopolia japonica)은 백아산 동북쪽 사면인 송단리 계곡을 중심으로 군데군데 큰 집단을 이루 고 있다. 송단리 계곡에는 털조장나무(Fig. 2D)도 몇 개체 씩 흩어져서 자라고 있다. 매미꽃은 백아산 주요 계곡 주 변에 큰 집단을 이루며 넓게 자라고 있다. 나도물통이는 그늘진 계곡부에서 작은 무리를 지어 자라며, 용곡리 냇가 와 인가 근처에서도 집단으로 자생하고 있는 것을 확인하 였다. 꽃창포(Iris ensata var. spontanea)는 송단에서 방리로 가는 길목의 논둑에 군락으로 자생하는 것을 확인하였다.
Table 5. The list of rare plants in Mt. Baekasan.

\begin{tabular}{|c|c|}
\hline Criteria & Taxa \\
\hline EN & $\begin{array}{l}\text { Jeffersonia dubia (Maxim.) Benth. \& Hook. f. ex Baker \& S. } \\
\text { Moore 깽깽이풀 }\end{array}$ \\
\hline DD & $\begin{array}{l}\text { Athyrium deltoidofrons Makino 구슬개고사리 } \\
\text { Carex ligulata Nees 갈사초 } \\
\text { Chloranthus fortunei (A. Gray) Solms옥녀꽃대 }\end{array}$ \\
\hline VU & $\begin{array}{l}\text { Pyrrosia hastata (Thunb) Ching 세뿔석 위 } \\
\text { Cremastra variabilis (Blume) Nakai ex Shibata 약난초 }\end{array}$ \\
\hline LC & $\begin{array}{l}\text { Scopolia japonica Maxim. 미치광이풀 } \\
\text { Scutellaria insignis Nakai 광릉골무꽃 } \\
\text { Lindera sericea (Siebold \& Zucc.) Blume 털조장나무 } \\
\text { Patrinia saniculaefolia Hemsl. 금마타리 } \\
\text { Chionanthus retusus Lindl. \& Paxton이팝나무 } \\
\text { Tricyrtis macropoda Miq. 뻐꾹나리 } \\
\text { Iris ensata var. spontanea (Makino) Nakai 꽃창포 } \\
\text { Coreanomecon hylomeconoides Nakai 매미꽃 } \\
\text { Viola albida Palib. 태백제비꽃 } \\
\text { Aristolochia contorta Bunge 쥐방울덩굴 } \\
\text { Arisaema heterophyllum Blume 두루미천남성 }\end{array}$ \\
\hline
\end{tabular}

$\overline{\mathrm{EN}}$, endangered species; DD, data deficient; VU, vulnerable; LC, least concern.

Table 6. Red list of endangered plants in Mt. Baekasan.

\begin{tabular}{|c|c|}
\hline Criteria & Таха \\
\hline NT & $\begin{array}{l}\text { Cremastra variabilis (Blume) Nakai ex Shibata 약난초 } \\
\text { Jeffersonia dubia (Maxim.) Benth.\& Hook.f.ex } \\
\text { Baker\&S.Moore 깽깽이풀 }\end{array}$ \\
\hline VU & Diplazium hachijoense Nakai 섬잔고사리 \\
\hline $\mathrm{LC}$ & $\begin{array}{l}\text { Chionanthus retusus Lindl. \& Paxton 이팝나무 } \\
\text { Cymbidium goeringii (Rchb. f.) Rchb. f. 보춘화 } \\
\text { Tricyrtis macropoda Miq. 뻐꾹나리 }\end{array}$ \\
\hline NE & $\begin{array}{l}\text { Athyrium deltoidofrons Makino구슬개고사리 } \\
\text { Carex ligulata Nees 갈사초 }\end{array}$ \\
\hline
\end{tabular}
NT, near threatened; VU, vulnerable; LC, least concern; NE, not evaluated.

\section{희귀식물}

백아산에서 조사된 희귀식물은 총 17 분류군으로 국립 수목원에서 지정한 희귀식물(Korea Forest Service, 2015) 557 분류군의 $3.1 \%$ 에 해당한다. 위기종(endangered species) 으로 깽깽이풀(Fig. 2A) 1분류군, 자료부족종(data deficient) 으로 구슬개고사리, 갈사초, 옥녀꽃대(Chloranthus fortunei) 3 분류군, 취약종(vulnerable)으로 세뿔석위, 약난초 2 분류 군, 약관심종(least concern)으로 미치광이풀, 꽃창포 등 11 분류군을 확인하였다(Table 5).

\section{적색목록}

적색목록에 속하는 관속식물은 총 8 분류군으로 환경부 국립생물자원관에서 지정한 적색목록(National Institute of Biological Resources, 2012) 543분류군의 $1.5 \%$ 에 해당한다. 

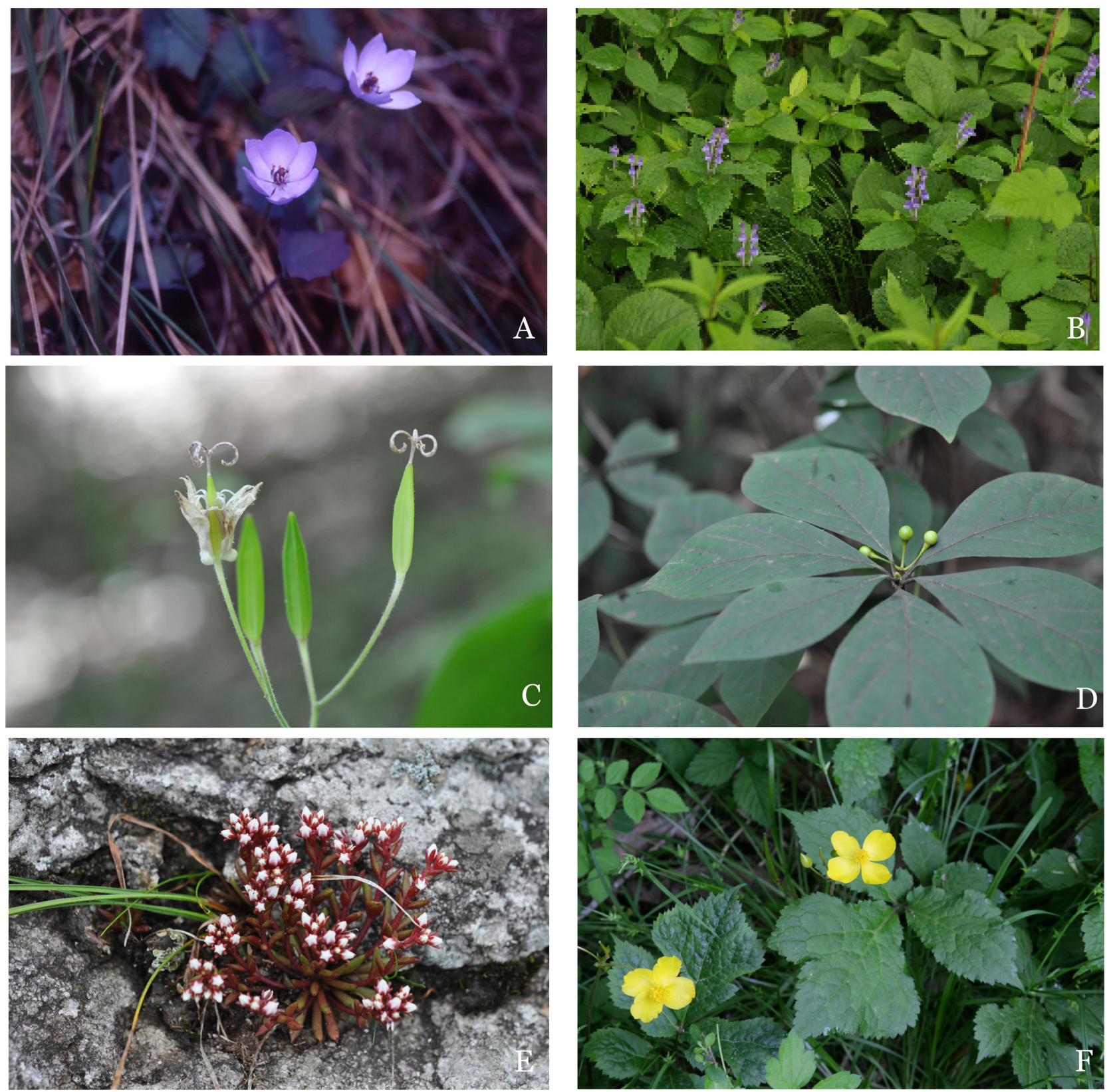

Fig. 2. Six remarkable plants in Mt. Baekasan. A. Jeffersonia dubia (Maxim.) Benth. \& Hook.f. ex Baker \& S. Moore. B. Scutellaria insignis Nakai. C. Tricyrtis macropoda Miq. D. Lindera sericea (Siebold \& Zucc.) Blume. E. Meterostachys sikokianus (Makino) Nakai. F. Hylomecon hylomeconoides Nakai.

백아산에서 확인된 적색목록에 속하는 관속식물은 준위 협종(near threatened)으로 약난초, 깽깽이풀의 2분류군, 취 약종으로 섬잔고사리 1 분류군, 약관심종은 이팝나무 (Chionanthus retusus), 보춘화(Cymbidium goeringii), 뻐꾹나 리(Tricyrtis macropoda) 3분류군, 미평가종(not evaluated)으 로 구슬개고사리, 갈사초 2 분류군이다(Table 6). 백아산 서 쪽사면의 계곡부와 임상에서 뻐꾹나리(Fig. 2C)의 자생지 를 확인하였다.

\section{호석회식물}

토양은 식물생육의 기초가 되는 물리적 환경으로 식물 분포를 결정하는 중요한 요인이다. 석회암지역은 모암의 특성상 다량의 칼슘과 탄산이온을 함유하고(Horak and Kinzel, 1971; Kim et al., 1990), 마그네슘 함량이 높은 알칼 리성 토양이 주를 이룬다. 대부분의 식물은 중성 및 약알 칼리성 토양을 선호하는 경향이 있어서 석회암지역은 희 귀식물의 피난처로 기능한다(Korea National Arboretum, 
Table 7. The list of calciferous plants in Mt. Baekasan.

\begin{tabular}{ll}
\hline \hline & Family \\
\hline Aspleniaceae 꼬리고사리과 & Taxplenium ruprechtii Sa. Kurata 거미고사리 \\
Cupressaceae 측백나무과 & Juniperus rigida Siebold \& Zucc. 노간주나무 \\
Fagaceae 참나무과 & Quercus variabilis Blume 굴참나무 \\
Ulmaceae 느릅나무과 & Ulmus davidiana var. japonica (Rehder) Nakai 느릅나무 \\
Moraceae 뽕나무과 & Morus cathayana Hemsl. 돌뽕나무 \\
Ranunculaceae 미나리아재비과 & Clematis brachyura Maxim. 외대으아리 \\
Euphorbiaceae 대극과 & Euphorbia sieboldiana Morren \& Decne 개감수 \\
Compositae 국화과 & Echinops setifer Iljin 절굿대 \\
Liliaceae 백합과 & Smilax sieboldii Miq. 청가시덩굴 \\
\hline
\end{tabular}

Table 8. The list of naturalized plants in Mt. Baekasan.

\begin{tabular}{|c|c|}
\hline Family & Taxa \\
\hline Phytolaccaceae 자리공과 & Phytolacca americana L. 미국자리공 \\
\hline Amaranthaceae 비름과 & Amaranthus lividus L. 개비름 \\
\hline Polygonaceae 마디풀과 & Rumex acetosella L. 애기수영 \\
\hline Cruciferae 십자화과 & $\begin{array}{l}\text { Brassica juncea (L.) Czern. 갓 } \\
\text { Thlaspi arvense L. 말냉이 }\end{array}$ \\
\hline Leguminosae 콩과 & $\begin{array}{l}\text { Amorpha fruticosa L. 족제비싸리 } \\
\text { Astragalus sinicus L. 자운영 } \\
\text { Robinia pseudoacacia } \text { L. 아까시나무 } \\
\text { Trifolium pratense L. 붉은토끼풀 } \\
\text { T. repens L. 토끼풀 }\end{array}$ \\
\hline Solanaceae 가지과 & Solanum nigrum L. 까마중 \\
\hline Convolvulaceae 메꽃과 & Quamoclit coccinea Moench 둥근잎유홍초 \\
\hline Labiatae 꿀풀과 & Lamium purpureum L. 자주광대나물 \\
\hline Scrophulariaceae 현삼과 & $\begin{array}{l}\text { Veronica arvensis L. 선개불알풀 } \\
\text { Veronica hederaefolia } \mathrm{L} \text {. 눈개불알풀 } \\
\text { Veronica persica Poir. 큰개불알풀 }\end{array}$ \\
\hline Compositae 국화과 & $\begin{array}{l}\text { Ambrosia artemisiifolia L. 돼지풀 } \\
\text { Chrysanthemum leucanthemum L. 불란서국화 } \\
\text { Conyza canadensis (L.) Cronquist 망초 } \\
\text { Coreopsis tinctoria Nutt. 기생초 } \\
\text { Erigeron annuus (L.) Pers. 개망초 } \\
\text { Galinsoga ciliate (Raf.) S. F. Blake. 털별꽃아재비 }\end{array}$ \\
\hline & $\begin{array}{l}\text { Senecio vulgaris L. 개쑥갓 } \\
\text { Solidago serotina Aiton 미국미역취 } \\
\text { Sonchus asper (L.) Hill 큰방가지똥 } \\
\text { S. oleraceus } \text { L. 방가지똥 } \\
\text { Taraxacum officinale Weber 서양민들레 }\end{array}$ \\
\hline Gramineae 벼과 & $\begin{array}{l}\text { Bromus tectorum L. 털빕새귀리 } \\
\text { Dactylis glomerata L. 오리새 } \\
\text { Lolium multiflorum Lam. 쥐보리 } \\
\text { L. perenne L. 호밀풀 }\end{array}$ \\
\hline
\end{tabular}

2012). 한반도의 경우 빙하기에는 북방계식물이 남방계식 물을 밀어 내리면서 남쪽으로 분포를 확장하고, 간빙기에 는 남방계식물이 북방계식물을 밀어 올리면서 북쪽으로 분포를 확장하게 된다. 이 과정 중 고산 정상 부근이나 석
회암지대 같은 특수지역은 쫓겨가는 식물들이 남아 숨게 되는 피난처로 기능한다. 우리나라의 석회암지대는 강원 도 남부, 충청북도 북부, 경상북도 북부를 중심으로 발달 되어 있다. 백아산은 정상부근에 석회암 노두가 있고, 내 
복천에 면한 남사면에는 석회동굴이 형성되어 있어서 면 적은 넓지 않으나 석회암지역으로 판단할 수 있다. 백아 산에서 확인된 식물 중 석회암지대식물로 인식되고 있는 종은 거미고사리(Asplenium ruprechtii), 노간주나무(Juniperus rigida) 등 9분류군으로 국립수목원의 석회암지대의 식물 (Korea National Arboretum, 2012)에서 언급된 호석회식물 109 분류군의 $7.3 \%$ 에 불과하다(Table 7). 백아산의 호석회 식물의 숫자가 예상보다 적은 이유는 석회암지역의 면적 이 좁고, 오랜 기간 풍화가 진행되어 토양 산도가 낮아졌 기 때문으로 보인다.

\section{귀화식물}

생태계교란야생식물인 돼지풀(Ambrosia artemisiifolia) 과 애기수영(Rumex acetosella)을 포함하여 33 분류군의 귀 화식물을 확인하였다(Table 8). 우리나라에 분포하는 귀화 식물 321분류군의(Park, 1995) $10.3 \%$ 에 해당한다. 백아산 은 산록을 따라 마을과 경작지가 이어져 있으며, 최근에 는 귀농현상과 겹쳐서 과수원과 약초원이 산중턱까지 넓 혀지고 있는 추세이다. 또한 자연휴양림과 눈썰매장 등 휴양 및 위락시설이 운영되고 있어서 주요 계곡과 능선을 따라 임도와 등산로가 종횡으로 개설되어 있다. 전체적으 로 인위적 간섭이 심해지고 있어 임도와 등산로를 따라 귀화식물이 자라는 것으로 판단된다.

\section{고 찰}

백아산은 그렇게 크거나 높은 산은 아니지만 온대산악 지대의 식물과 남해안 도서지방의 식물이 공존하고 있는 지역으로서 식물분류학 및 식물지리학적 측면에서 매우 중요한 지역이다. 산록부의 개발과 휴양림을 중심으로 한 등산객 유입은 백아산의 종다양성과 식생 전반에 상당한 압박을 미치고 있을 것으로 생각된다. 석회석 광산의 흔 적은 아직도 깊은 상처로 남아 있으며 군립공원을 중심으 로 한 탐방로 구간 중에는 지속적인 답압 피해가 우려되 는 곳도 있다. 백아산의 학술적 중요성을 고려하여 기존 의 숲에 더 이상 압박을 가하는 일이 없도록 신중을 기해 야 할 것이다.

\section{Acknowledgments}

This work was supported by a grant from the National Institute of Biological Resources (NIBR), funded by the Ministry of Environment (MOE) of the Republic of Korea (NIBR201601202).

\section{Literatures Cited}

Horak, O. and H. Kinzel. 1971. Typen des mineralstoffwechsels bei den Hoheren Pflanzen. Österreichische Botanische Zeitschrift 119: 475-495.

Kim, J.-H. H.-T. Mun and Y.-S. Kwak. 1990. Community structure and soil properties of the Chinese cork oak (Quercus variabilis) forests in the limestone areas. Korean Journal of Ecology 13: 285-295. (in Korean)

Kim, H. G. 2003. The physical and shear strength properties of the weathered limestone soils in Changsung and Hwasun of Chonnam Province, Korea. The Journal of Engineering Geology 13: 335-344.

Korea Forest Service. 2015. Act on the creation and furtherance of arboretums and gardens. Act No. 132027.

Korea National Arboretum and The Plant Taxonomic Society of Korea. 2007. A Synonymic List of Vascular Plants in Korea. Korea National Arboretum, Pocheon, 534 pp. (in Korean)

Korea National Arboretum. 2012. The Plants in Limestone Areas. Geobook, Seoul, 143 pp. (in Korean)

Lee, Y.-M., S.-H. Park, S.-Y. Jung, S.-H. Oh and J.-C. Yang. 2011. Study on the current status of naturalized plants in South Korea. Korean Journal of Plant Taxonomy 41:87-101. (in Korean)

Lee, W. T. and Y. H. Lim. 1978. Studies on the distribution of vascular plants in the Korean Peninsula. Korean Journal of Plant Taxonomy 8:1-33. (in Korean)

Ministry of Environment and National Institute of Environmental Research. 2014. Forth Round of the National Natural Environmental Research Guidelines. Ministry of Environment and National Institute of Environmental Research, Gwacheon \& Incheon, pp. 173-226. (in Korean)

National Institute of Biological Resources. 2012. Red Data Book of Endangered Vascular Plants in Korea. Econature, Seoul, 174 pp. (in Korean)

Oh, B. U., S. C. Ko, S. H. Kang, W. G. Paik, K. O. Yoo, H. T. Im, C. G. Jang, G. Y. Chung. B. H. Choi and H. J. Choi. 2016. Distribution Maps of Vascular Plants in Korea. Korea National Arboretum, Pocheon, 809 pp. (in Korean)

Park, C.-W. 2007. The Genera of Vascular Plants of Korea. Academy Publ. Co., Seoul, 1482 pp. (in Korean)

Park. J. W. and M. H. Kim. 2005. A Flora of Hwasun and GokSeong. Report on the Second Round of the National Natural Environmental Research. Ministry of Environment, Seoul. Pp. 125-151. (in Korean)

Park, S. H. 1970. The investigation of Mt. Moo-Dung Flora. Korean Journal of Plant Taxonomy 2: 23-39 (in Korean).

Park, S. H. 1995. Coloured Illustrated Guide to Naturalized Plant of Korea. Ilchogak, Seoul, 371 pp. (in Korean) 
Appendix 1. Flora of Mt. Baeka.

\begin{tabular}{llll}
\hline \hline Taxa & Korean name & Voucher number & Category \& Criteria
\end{tabular}

Lycopodiaceae 석송과

Lycopodium serratum Thunb.

Selaginellaceae 부처손과

Selaginella rossii (Baker) Warb.

Equisetaceae 속새과

Equisetum arvense $\mathrm{L}$.

\section{Ophioglossaceae 고사리삼과}

Sceptridium japonicum (Pantl.) Lyon

Sceptridium ternatum (Tnub.) Lyon

\section{Osmundaceae 고비과}

Osmunda cinnamomea var. forkiensis Copel.

Osmunda japonica Thunb.

\section{Pteridaceae 봉의꼬리과}

Coniogramme japonica (Thunb.) Diels

\section{Dennstaedtiaceae 잔고사리과}

Dennstaedtia hirsuta (Sw.) Mett. ex Miq.

Dennstaedtia wilfordii (Moore) Christ.

Pteridium aquilinum var. latiusculum (Desv.) Underw. ex Hell.

\section{Aspleniaceae 꼬리고사리과}

Asplenium incisum Thunb.

Asplenium ruprechtii Sa. Kurata

Onocleaceae 야산고비과

Matteuccia orientalis (Hook.) Trevis.

\section{Woodsiaceae 우드풀과}

Woodsia manchuriensis Hook.

Woodsia polystichoides D.C.Eaton

\section{Athyriaceae 개고사리과}

Athyrium deltoidofrons Makino

Athyrium niponicum (Mett.) Hance

Athyrium vidalii (Franch. et Sav.) Nakai

Athyrium yokoscense (Franch.et Sav.) Christ

Cornopteris crenulato-serrulata (Makino) Nakai

Deparia conilii (Franch.et Sav.) M.Kato

Deparia coreana (Christ) M. Kato

Deparia japonica (Thunb.) M. Kato.

Deparia lasiopteris (Kunze) Nakaike

Deparia petersenii (Kunze) M. Kato

Diplazium hachijoense Nakai

Polystichum ovatopaleaceum (Kodama) Sa.Kurata

$\begin{array}{cc}\text { 뱀톱 } & \operatorname{Im} 100153 \\ \text { 구실사리 } & \operatorname{Im} 090352 \\ \text { 쇠뜨기 } & \text { IP } 160293 \\ & \\ \text { 산꽃고사리삼 } & \text { IP } 080842 \\ \text { 고사리삼 } & \text { IP } 134982 \\ \text { 꿩고비 } & \\ \text { 고비 } & \text { IP } 160213 \\ & \operatorname{Im} 100126\end{array}$

가지고비고사리 $\quad$ Im 100128

IP 160570

잔고사리

Im 039062

고사리

Im 039064

$\begin{array}{ll}\text { 꼬리고사리 } & \operatorname{Im} 140710 \\ \text { 거미고사리 } & \operatorname{Im} 135307\end{array}$

개면마 $\quad \operatorname{Im} 090020$

$\begin{array}{cc}\text { 만주우드풀 } & \operatorname{Im} 090356 \\ \text { 우드풀 } & \operatorname{Im} 039086\end{array}$

$\begin{array}{ccc}\text { 구슬개고사리 } & \text { Im } 140362 & \mathrm{~V}, \mathrm{DD}, \mathrm{NE} \\ \text { 개고사리 } & \text { IP } 134891 & \\ \text { 산개고사리 } & \text { IP } 160339 & \\ \text { 뱀고사리 } & \operatorname{Im} 140395 \\ \text { 응달고사리 } & \text { IP } 160329 & \\ \text { 좀진고사리 } & \text { Im } 039054 & \\ \text { 곱새고사리 } & \text { IP } 160323 & \\ \text { 진고사리 } & \text { IP } 134868 & \\ \text { 큰진고사리 } & \text { IP } 140650 & \text { IV, VU } \\ \text { 탐라진고사리 } & \text { IP } 140638 & \\ \text { 섬잔고사리 } & \text { Im } 140644 & \\ \text { 지리개관중 } & \text { IP } 134897 & \end{array}$


Appendix 1. Continued.

\begin{tabular}{|c|c|c|c|}
\hline Taxa & Korean name & Voucher number & Category \& Criteria \\
\hline \multicolumn{4}{|l|}{ Thelypteridaceae 처녀고사리과 } \\
\hline Phegopteris decursivepinnata (H.C. Hall) Fee. & 설설고사리 & Im 135298 & \\
\hline Thelypteris glandeuligera (Kunze) Ching & 사다리고사리 & Im 100167 & I \\
\hline Thelypteris japonca (Baker)Ching & 지네고사리 & Im 140392 & \\
\hline Thelypteris viridefrons Tagawa & 푸른각시고사리 & IP 160345 & \\
\hline \multicolumn{4}{|l|}{ Dryopteridaceae 관중과 } \\
\hline Arachniodes borealis Seriz. & 왁살고사리 & IP 160359 & \\
\hline Cyrtomium fortunei J. Sm. & 쇠고비 & IP 134879 & I \\
\hline Dryopteris bissetiana (Baker) C. Chr. & 산족제비고사리 & IP 160188 & \\
\hline Dryopteris crassirhizoma Nakai & 관중 & Im 100154 & I \\
\hline Dryopteris erythrosora (D.C. Eaton) Kuntze & 홍지네고사리 & Im 140373 & I \\
\hline Dryopteris gymnopylla (Baker) C. Chr. & 금족제비고사리 & Im 140469 & III \\
\hline Dryopteris lacera (Thunb.)Kuntze & 비늘고사리 & IP 134893 & \\
\hline Dryopteris monticola (Makino) C. Chr. & 왕지네고사리 & IP 160350 & \\
\hline Dryopteris sacrosancta Koidz. & 애기족제비고사리 & IC 134866 & \\
\hline Dryopteris saxifraga H.Ito & 바위족제비고사리 & IP 134867 & \\
\hline Dryopteris simasakii var. paleacea (H. Ito) Sa. Kurata & 층층지네고사리 & IP 140367 & \\
\hline Dryopteris uniformis (Makino) Makino & 곰비늘고사리 & IP 160362 & I \\
\hline Polystichum polyblepharum (Roem. ex Kuntze) C. Presl & 나도히초미 & IP 160510 & \\
\hline Polystichum tripteron (Kunze) C. Presl & 십자고사리 & IP 160325 & \\
\hline \multicolumn{4}{|l|}{ Davalliaceae 넉줄고사리과 } \\
\hline Davallia mariesii T. Moore ex Baker & 넉줄고사리 & Im 039060 & \\
\hline \multicolumn{4}{|l|}{ Polypodiaceae 고란초과 } \\
\hline Lepisorus thunbergianus (Kaulf.) Ching & 일엽초 & Im 140593 & \\
\hline Lepisorus ussuriensis (Regel et Maack.) Ching & 산일엽초 & Im 090355 & \\
\hline Pyrrosia hastata (Thunb.) Ching & 세뿔석위 & IP 80843 & III, VU \\
\hline \multicolumn{4}{|l|}{ Pinaceae 소나무과 } \\
\hline Larix kaempferis (Lamb.) Carriere & 일본잎갈나무(재) & Im 012545 & \\
\hline Pinus densiflora Siebold et Zucc. & 소나무 & Im 090324 & \\
\hline Pinus rigida Mill. & 리기다소나무 & Im 100168 & \\
\hline \multicolumn{4}{|l|}{ Cupressaceae 측백나무과 } \\
\hline Chamaecyparis obtusa (Siebold et Zucc.) Endl. & 편백(재) & Im 090042 & \\
\hline Cryptomeria japonica (Thunb.ex L.f.) D. Don & 삼나무(재) & C 012580 & \\
\hline Juniperus rigida Siebold \& Zucc. & 노간주나무 & Im 100124 & \\
\hline \multicolumn{4}{|l|}{ Cephlaotaxaceae 개비자나무과 } \\
\hline Cephalotaxus koreana Nakai & 개비자나무 & IP 160352 & I \\
\hline \multicolumn{4}{|l|}{ Magnoliaceae 목련과 } \\
\hline Magnolia sieboldii K. Koch. & 함박꽃나무 & IP 160576 & \\
\hline \multicolumn{4}{|l|}{ Lauraceae 녹나무과 } \\
\hline Lindera erythrocarpa Makino & 비목나무 & C 012023 & \\
\hline Lindera glauca (Siebold \& Zucc.)Blume & 감태나무 & Im 039990 & \\
\hline
\end{tabular}


Appendix 1. Continued.

\begin{tabular}{|c|c|c|c|}
\hline Taxa & Korean name & Voucher number & Category \& Criteria \\
\hline Lindera obtusiloba Blume & 생강나무 & IP 160195 & \\
\hline Lindera sericea (Siebold et Zucc.) Blume & 털조장나무 & IP 134869 & IV, LC \\
\hline \multicolumn{4}{|l|}{ Chloranthaceae 흘아비꽃대과 } \\
\hline Chloranthus fortunei (A.Gray) Solms & 옥녀꽃대 & IP 160223 & I, DD \\
\hline \multicolumn{4}{|l|}{ Aristolochiaceae 쥐방울덩굴과 } \\
\hline Aristolochia contorta Bunge & 쥐방울덩굴 & C 140001 & $\mathrm{I}, \mathrm{LC}$ \\
\hline Asarum sieboldii Miq. & 족도리풀 & IP 160308 & \\
\hline \multicolumn{4}{|l|}{ Ranunculaceae 미나리아재비과 } \\
\hline Aconitum jaluense Kom. & 투구꽃 & Im 140470 & I \\
\hline Actaea asiatica $\mathrm{H}$. Hara & 노루삼 & IP $160419 a, b$ & \\
\hline Adonis amurensis Regel et Radde & 복수초 & IP 160517 & \\
\hline Clematis apiifolia DC. & 사위질빵 & Im 140494 & \\
\hline Clematis brachyura Maxim. & 외대으아리 & C 012102 & $\mathrm{E}$ \\
\hline Clematis terniflora var. mandshurica (Rupr.) Maxim. & 으아리 & IP 160559 & \\
\hline Clematis patens C. Morren et Decne. & 큰꽃으아리 & C 012096 & I \\
\hline Clematis trichotoma Nakai & 할미밀망 & IP 160328 & $\mathrm{E}$ \\
\hline Ranuculus cantoniensis DC. & 털개구리미나리 & Im 140932 & \\
\hline Ranuculus chinensis Bunge & 젓가락나물 & Im 140773 & \\
\hline Ranuculus tachiroei Franch. et Sav. & 개구리미나리 & Im 140771 & \\
\hline Ranuculus japonicus Thunb. & 미나리아재비 & IP 160388 & \\
\hline Semiaquilegia adoxoides (DC.) Makino & 개구리발톱 & IE 134838 & I \\
\hline Thalictrum actaefolium var. brevistylum Nakai & 은꿩의다리 & Im 140478 & \\
\hline $\begin{array}{l}\text { Thalictrum kemense var. hypoleucum (Siebold et Zucc.) } \\
\text { Kitag. }\end{array}$ & 좀꿩의다리 & Im 140931 & \\
\hline \multicolumn{4}{|l|}{ Berberidaceae 매자나무과 } \\
\hline Caulophyllum robustum Maxim. & 꿩의다리아재비 & Im 140552 & II \\
\hline $\begin{array}{l}\text { Jeffersonia dubia (Maxim.) Benth. \& Hook. ex Baker \& } \\
\text { S. Moore }\end{array}$ & 깽깽이풀 & IC 985125 & $\mathrm{~V}, \mathrm{EN}, \mathrm{NT}$ \\
\hline \multicolumn{4}{|l|}{ Menispermaceae 새모래덩굴과 } \\
\hline Cocculus trilobus (Thunb.)DC. & 댕댕이덩굴 & Im 012014 & \\
\hline \multicolumn{4}{|l|}{ Lardizabalceae 으름덩굴과 } \\
\hline Akebia quinata (Houtt.)Decne. & 으름덩굴 & C 012020 & \\
\hline \multicolumn{4}{|l|}{ Papaveraceae 양귀비과 } \\
\hline Chelidonium majus var. asiaticum (H. Hara) Ohwi & 애기똥풀 & C 012049 & \\
\hline Coreanomecon hylomeconoides Nakai & 매미꽃 & IE 134842 & E, IV, LC \\
\hline \multicolumn{4}{|l|}{ Fumariaceae 현호색과 } \\
\hline Corydalis incisa (Thunb.) Pers. & 자주괴불주머니 & Im 140897 & \\
\hline Corydalis pauciovulata Ohwi & 선괴불주머니 & IP 160198 & \\
\hline Corydalis remota Fisch. ex Maxim. & 현호색 & IP 90360 & \\
\hline Corydalis speciosa Maxim. & 산괴불주머니 & IP 160186 & \\
\hline
\end{tabular}


Appendix 1. Continued.

\begin{tabular}{|c|c|c|c|}
\hline Taxa & Korean name & Voucher number & Category \& Criteria \\
\hline Corydalis turtschaninovii Besser. & 조선현호색 & IP 160555 & \\
\hline Dicentra spectabilis (L.) Lem. & 금낭화 & Im 140771 & \\
\hline \multicolumn{4}{|l|}{ Ulmaceae 느릅나무과 } \\
\hline Celtis sinensis Pers. & 팽나무 & Im 039021 & \\
\hline Ulmus davidiana var. japonica (Rehder) Nakai & 느릅나무 & Im 140816 & \\
\hline Zelkova serrata Makino & 느티나무 & C 039019 & \\
\hline \multicolumn{4}{|l|}{ Cannabinaceae 삼과 } \\
\hline Humulus japonicus Siebold et Zucc. & 환삼덩굴 & C 011976 & \\
\hline \multicolumn{4}{|l|}{ Moraceae 뽕나무과 } \\
\hline Broussonetia kazinoki Sieb. & 닥나무 & IP 135289 & \\
\hline Broussonetia papyrifera (L.) Vent. & 꾸지나무 & C 039016 & \\
\hline Cudrania tricuspidata Bureau ex Lavallee & 꾸지뽕나무 & $\operatorname{Im} 140558$ & \\
\hline Morus bombycis Koidz. & 산뽕나무 & Е 90103 & \\
\hline Morus cathayana Hemsl. & 돌뽕나무 & Im 135293 & II \\
\hline \multicolumn{4}{|l|}{ Urticaceae 쐐기풀과 } \\
\hline Boehmeria nivea (L.) Gaudich & 모시풀 & Im 135316 & \\
\hline Boehmeria spicata (Thunb.)Thunb. & 좀깨잎나무 & C 011981 & \\
\hline Boehmeria platanifolia Franch. et Sav. & 개모시풀 & $\operatorname{Im} 140110$ & \\
\hline Boehmeria tricuspis (Hance) Makino & 거북꼬리 & $\operatorname{Im} 140536$ & \\
\hline Laportea bulbifera (Siebold et Zucc.) Wedd. & 혹쐐기풀 & Im 140370 & \\
\hline Nanocnide japonica Blume & 나도물통이 & C 011977 & I \\
\hline Pilea mongolica Wedd. & 모시물통이 & $\operatorname{Im} 140357$ & \\
\hline Urtica angustifolia Fisch. ex Hornem. & 가는잎쐐기풀 & Im 100121 & \\
\hline \multicolumn{4}{|l|}{ Fagaceae 참나무과 } \\
\hline Castanea crenata Siebold et Zucc. & 밤나무 & Im 039025 & \\
\hline Quercus dentata Thunb. ex Murray & 떡갈나무 & Im 012001 & \\
\hline Quercus acutissima Carruth. & 상수리나무 & C 012004 & \\
\hline Quercus mongolica Fisch. & 신갈나무 & $\operatorname{Im} 140822$ & \\
\hline Quercus serrata Murray & 졸참나무 & Im 140822 & \\
\hline Quercus variabilis Blume & 굴참나무 & Im 100158 & \\
\hline \multicolumn{4}{|l|}{ Betulaceae 자작나무과 } \\
\hline Alnus japonica (Thunb.) Steud. & 오리나무 & Im 100162 & \\
\hline Alnus hirsuta Fisch ex Turcz. & 물오리나무 & Im 140496 & \\
\hline Betula ermani Cham. & 사스래나무 & $\operatorname{Im} 100163$ & \\
\hline Corylus sieboldiana Blume & 참개암나무 & IP 160340 & \\
\hline Corylus heterophylla Fisch. Ex Trautv. & 개암나무 & IP 160387 & \\
\hline Carpinus cordata Blume & 까치박달 & Im 134867 & \\
\hline Carpinus laxiflora (Siebold \&Zucc.) Blume & 서어나무 & Im 135368 & \\
\hline Carpinus tschonoskii Maxim. & 개서어나무 & $\operatorname{Im} 021718$ & \\
\hline
\end{tabular}


Appendix 1. Continued.

\begin{tabular}{|c|c|c|c|}
\hline Taxa & Korean name & Voucher number & Category \& Criteria \\
\hline \multicolumn{4}{|l|}{ Phytolacaceae 자리공과 } \\
\hline Phytolaca americana $\mathrm{L}$. & 미국자리공 & C 012076 & $\mathrm{~N}$ \\
\hline \multicolumn{4}{|l|}{ Chenopodiaceae 명아주과 } \\
\hline Chenopodium album var. centrorubrum Makino & 명아주 & Im 135339 & \\
\hline \multicolumn{4}{|l|}{ Amaranthaceae 비름과 } \\
\hline Achyranthes japonica (Miq.) Nakai & 쇠무릎 & Im 140629 & \\
\hline Amaranthus lividus $\mathrm{L}$. & 개비름 & C 012077 & $\mathrm{~N}$ \\
\hline
\end{tabular}

\section{Caryophyllaceae 석죽과}

Cerastium holosteoides var. hallaisanense (Nakai) Mizushima

$\begin{array}{cc}\text { 점나도나물 } & \text { Im } 090060 \\ \text { 유럽점나도나물 } & \mathrm{C} 140993 \\ \text { 패랭이꽃 } & \mathrm{C} 134833 \\ \text { 술패랭이꽃 } & \mathrm{C} 012087 \\ \text { 개별꽃 } & \mathrm{IP} 160227 \\ \text { 큰개별꽃 } & \mathrm{Im} 140885 \\ \text { 장구채 } & \mathrm{Im} 100136 \\ \text { 가는장구채 } & \mathrm{Im} 140557 \\ \text { 벼룩나물 } & \mathrm{C} 012080 \\ \text { 쇠별꽃 } & \mathrm{C} 012078 \\ \text { 별꽃 } & \mathrm{Im} 140779\end{array}$

Polygonaceae 마디풀과

Bistorta manshuriensis (Petrov.ex Kom.) Kom.

Fallopia cilinervis (Nakai) Hammer

Fallopia multiflorus (Thurb.) Haraldson

Persicaria filiforme Nakai ex Mori

Persicaria hydropiper (L.) Delarbre

Persicaria lapathifolia (L.) Delarbre

Persicaria longiseta (Bruijn) Kitag.

Persicaria posumbu var. laxiflora (Melsn.) H. Hara

Persicaria pubescens (Blume) H. Hara

Persicaria dissiflora (Hemsl.) H. Gross ex Mori

Persicaria nepalensis (Meisn.) H. Gross

Persicaria perfoliata (L.) H. Gross

Persicaria senticosa (Melsn.) H. Gross ex Nakai

Persicaria sagittata (L.) H. Gross

Persicaria thunbergii (Siebold et Zucc.) H.Gross

Persicaria viscosa (Buch-Ham. ex D.Don) H. Gross ex Nakai

$\begin{array}{cr}\text { 범꼬리 } & \text { C } 012028 \\ \text { 나도하수오 } & \text { C } 141000 \\ \text { 하수오 } & \text { Im } 140762 \\ \text { 이삭여뀌 } & \text { Im } 105532 \\ \text { 여뀌 } & \text { C } 039996 \\ \text { 흰여뀌 } & \text { Im } 140606 \\ \text { 개여뀌 } & \text { Im } 140448 \\ \text { 장대여뀌 } & \text { C } 012034 \\ \text { 바보여뀌 } & \text { Im } 1246 \\ \text { 가시여뀌 } & \text { Im } 039997 \\ \text { 산여뀌 } & \text { Im } 140479 \\ \text { 며느리배꼽 } & \text { C } 039994 \\ \text { 며느리밑씻개 } & \text { C } 012036 \\ \text { 미꾸리낚시 } & \text { Im } 012037 \\ \text { 고마리 } & \text { IP } 100148 \\ \text { 기생여뀌 } & \text { C } 141003 \\ \text { 마디풀 } & \text { C } 012038 \\ \text { 애기수영 } & \text { IP } 160390\end{array}$

Polygonum aviculare L.

애기수영

IP 160390

$\mathrm{N}$ 
Appendix 1. Continued.

\begin{tabular}{|c|c|c|c|}
\hline Taxa & Korean name & Voucher number & Category \& Criteria \\
\hline Rumex conglomeratus Murray & 묵밭소리쟁이 & C 140995 & \\
\hline Rumex acetosa $\mathrm{L}$. & 수영 & Im 140825 & \\
\hline \multicolumn{4}{|l|}{ Theaceae 차나무과 } \\
\hline Stewartia pseudocamellia Maxim & 노각나무 & C 140554 & E, III \\
\hline \multicolumn{4}{|l|}{ Actinidiaceae 다래나무과 } \\
\hline Actinida arguta (Siebold \& Zucc.) Planch. ex Miq. & 다래 & IP 160355 & \\
\hline Actinida kolomikta (Maxim. et Rupr.) Maxim. & 쥐다래 & IP 081122 & \\
\hline Actinida polygama (Siebold et Zucc.) Planch. ex Maxim & 개다래 & Im 140556 & \\
\hline \multicolumn{4}{|l|}{ Guttiferae 물레나물과 } \\
\hline Hypericum ascyron $\mathrm{L}$. & 물레나물 & Im 140552 & \\
\hline Hypericum erectum Thunb. & 고추나물 & Im 140495 & \\
\hline \multicolumn{4}{|l|}{ Tiliaceae 피나무과 } \\
\hline Corchoropsis tomentosa (Thunb.) Makino & 수까치깨 & IP 134804 & \\
\hline Grewia parviflora Bunge & 장구밤나무 & C 012257 & I \\
\hline Tilia amurensis Rupr. & 피나무 & Im 140558 & \\
\hline \multicolumn{4}{|l|}{ Flacourtiaceae 산유자나무과 } \\
\hline Idesia polycarpa Maxim. & 이나무 & Im 135299 & III \\
\hline \multicolumn{4}{|l|}{ Violaceae 제비꽃과 } \\
\hline Viola accuminata Ledeb. & 졸방제비꽃 & IP 34806 & \\
\hline Viola albida Palib & 태백제비꽃 & IP 160551 & $\mathrm{LC}$ \\
\hline Viola collina Besser & 둥근털제비꽃 & IP 160530 & \\
\hline $\begin{array}{l}\text { Viola dissecta var. chaerophylloides (Regel) F. Maek. ex } \\
\text { Hara }\end{array}$ & 남산제비꽃 & Im 160445 & \\
\hline Viola hirtipes S. Moore. & 흰털제비꽃 & IP 160533 & \\
\hline Viola japonica Langsd. ex Ging. & 왜제비꽃 & IP 160194 & \\
\hline Viola keiskei Miq. & 잔털제비꽃 & $\operatorname{Im} 160470$ & \\
\hline Viola mandshurica W. Becker & 제비꽃 & C 012224 & \\
\hline Viola patrinii Ging. & 흰제비꽃 & Im 135593 & \\
\hline Viola rossii Hemsl. & 고깔제비꽃 & Im 090123 & \\
\hline Viola variegata Fisch. ex Link & 알록제비꽃 & C 12221 & \\
\hline Viola variegata var. chinensis Bunge & 자주알록제비꽃 & IP 80856 & \\
\hline Viola verecunda A. Gray & 콩제비꽃 & IP 135338 & \\
\hline \multicolumn{4}{|l|}{ Cucurbitaceae 박과 } \\
\hline Gynostemma pentaphylla (Thunb.) Makino & 돌외 & Im 135339 & I \\
\hline Trichosanthes kirilowii Maxim. & 하늘타리 & C 012339 & \\
\hline \multicolumn{4}{|l|}{ Salicaceae 버드나무과 } \\
\hline Populus tomentiglandulosa T. B. Lee & 은사시나무(재) & Im 100126 & $\mathrm{E}$ \\
\hline Salix graciliglans Nakai & 눈갯버들 & IP 160200 & \\
\hline Salix koreensis Andersson & 버드나무 & Im 090275 & \\
\hline Salix integra Thunb. & 개키버들 & C 039046 & \\
\hline
\end{tabular}


Appendix 1. Continued.

\begin{tabular}{|c|c|c|c|}
\hline Taxa & Korean name & Voucher number & Category \& Criteria \\
\hline \multicolumn{4}{|l|}{ Cruciferae 십자화과 } \\
\hline Arabis glabra Bernh. & 장대나물 & C 134831 & \\
\hline Arabis hirtula (L.) Scop. & 털장대 & IE 134850 & \\
\hline Brassica juncea (L.) Czern. & 갓 & C 039227 & $\mathrm{~N}$ \\
\hline Cardamine flexuosa With. & 황새냉이 & Im 985104 & \\
\hline Cardamine fallax $\mathrm{L}$. & 좁쌀냉이 & Im 039224 & \\
\hline Cardamine impatiens $\mathrm{L}$. & 싸리냉이 & Im 039228 & \\
\hline Cardamine leucantha (Tausch) O.E. Schulz & 미나리냉이 & IE 134849 & \\
\hline Cardamine scutata Thunb. & 큰황새냉이 & C 012060 & \\
\hline Casella bursapastoris (L.) L.W. Medicus & 냉이 & IP 160187 & \\
\hline Dontostemon dentatus (Bunge) Ledeb. & 가는장대 & C 039775 & \\
\hline Rorippa indica (L.) Hiern & 개갓냉이 & C 012053 & \\
\hline Thlaspi arvense L. & 말냉이 & IC 985133 & $\mathrm{~N}$ \\
\hline \multicolumn{4}{|l|}{ Ericaceae 진달래과 } \\
\hline Rhododendron mucronulatum Turcz. & 진달래 & Im 135418 & \\
\hline Rhododendron mucronulatum var. ciliatum Nakai & 털진달래 & IP 160427 & \\
\hline Rhododendron schlippenbachii Maxim. & 철쭉 & Im 135377 & \\
\hline $\begin{array}{l}\text { Rhododendron yedoense f.poukhanense (H. Lev.) M. } \\
\text { Sugim. ex T. Yamaz }\end{array}$ & 산철쭉 & IP 160239 & \\
\hline Vaccinium oldhami Miq. & 정금나무 & IP 160284 & \\
\hline \multicolumn{4}{|l|}{ Pyrolacae 노루발과 } \\
\hline Chimaphila japonica Miq. & 매화노루발 & C 12205 & \\
\hline Pyrola japonica Klenze ex Alef. & 노루발 & Im 105533 & \\
\hline \multicolumn{4}{|l|}{ Ebenaceae 감나무과 } \\
\hline Diospyros lotus L. & 고욤나무 & C 044666 & \\
\hline \multicolumn{4}{|l|}{ Styracaceae 때죽나무과 } \\
\hline Styrax japonica Siebold et Zucc. & 때죽나무 & IP 160235 & \\
\hline Styrax obassia Siebold et Zucc. & 쪽동백나무 & IP 160322 & \\
\hline \multicolumn{4}{|l|}{ Symplicaceae 노린재나무과 } \\
\hline Symplocos tanakana Nakai & 검노린재 & Im 135371 & \\
\hline \multicolumn{4}{|l|}{ Primulaceae 앵초과 } \\
\hline Androsace umbellata (Lour.) Merr. & 봄맞이 & C 044999 & \\
\hline Lysimachia clethroides Duby & 큰까치수염 & Im 140665 & \\
\hline Lysimachia japonica Thunb. & 좀가지풀 & IP 160382 & \\
\hline \multicolumn{4}{|l|}{ Crassulaceae 돌나물과 } \\
\hline Meterostachys sikokianus (Makino) Nakai & 난쟁이바위솔 & Im 135337 & III \\
\hline Sedum aizoon $\mathrm{L}$. & 가는기린초 & IP 160585 & \\
\hline Sedum bulbiferum Makino & 말똥비름 & C 012072 & \\
\hline Sedum kamtschaticum Fisch. et Mey & 기린초 & C 012071 & \\
\hline Sedum polystichoides Hemsl. & 바위채송화 & Im 140596 & \\
\hline
\end{tabular}


Appendix 1. Continued.

\begin{tabular}{|c|c|c|c|}
\hline Taxa & Korean name & Voucher number & Category \& Criteria \\
\hline Sedum sarmentosum Bunge & 돌나물 & C 012068 & \\
\hline Hylotelepium verticillatum (L.) H. Ohba & 세잎꿩의비름 & Im 039338 & I \\
\hline \multicolumn{4}{|l|}{ Saxifragaceae범의귀과 } \\
\hline Astilbe rubra Hook. f. et Thomson & 노루오줌 & IP $160420 a, b$ & \\
\hline Chrysosplenium flagelliferum $\mathrm{F}$. Schmidt & 애기괭이눈 & IP 081120 & \\
\hline Deutzia glabrata Kom. & 물참대 & Im 140792 & \\
\hline Deutzia parviflora Bunge & 말발도리 & Im 140521 & \\
\hline Deutzia prunifolia Rehder & 바위말발도리 & Im 135432 & \\
\hline Deutzia uniflora Shirai & 매화말발도리 & IP 160539 & \\
\hline $\begin{array}{l}\text { Hydrangea serrata f. acuminata (Siebold et Zucc.) } \\
\text { E.H.Wilson }\end{array}$ & 산수국 & IP 160343 & \\
\hline Philadelphus pekinensis Rupr. & 애기고광나무 & Im $039331 \mathrm{I}$ & III \\
\hline Philadelphus tenuifolius Rupr. et Maxim. & 얇은잎고광나무 & IP 160547 & \\
\hline Ribes fasciculatum var. chinense Maxim. & 까마귀밥나무 & IP 160269 & \\
\hline Saxifraga fortunei var. incisolobata Nakai & 바위떡풀 & Im 140598 & \\
\hline \multicolumn{4}{|l|}{ Rosaceae 장미과 } \\
\hline Agrimonia pilosa Ledeb. & 짚신나물 & C 012135 & \\
\hline Duchesnea indica (Andr.) Focke & 뱀딸기 & IP 160519 & \\
\hline Geum aleppicum Jacq. & 큰뱀무 & Im 041750 & \\
\hline Kerria japonica f. pleniflora (Witte) Rehder. & 죽단화(재) & Im 985144 & \\
\hline Potentilla cryptotaenia Maxim & 물양지꽃 & Im 140540 & I \\
\hline Potentilla dickinsii Franch. et Sav. & 돌양지꽃 & Im 140592 & II \\
\hline Potentilla fragarioides var. major Maxim. & 양지꽃 & Im 090289 & \\
\hline Potentilla freyniana Bornm. & 세잎양지꽃 & IP 160248 & \\
\hline Potentilla anemonefolia Lehm. & 가락지나물 & IP 137002 & \\
\hline Potentilla yokusaiana Makino & 민눈양지꽃 & IP 90370 & \\
\hline Pourthiaea villosa (Thunb.) Decne. & 윤노리나무 & Im 105534 & \\
\hline Prunus glandulosa f. albiplena Koehne & 옥매 & C 041745 & \\
\hline Prunus mume Siebold et Zucc. & 매실나무 & IP 160296 & \\
\hline Prunus persica (L.) Batsch & 복사나무 & C 012130 & \\
\hline Prunus serrulata var. spontanea (Maxim.) E.H. Wilson & 벚나무 & IP 160229 & \\
\hline Prunus verecunda (Koidz) Koehne & 개벚나무 & IP 160421 & \\
\hline Pyrus calleryana var. fauriei (Schneid.) Rehder & 콩배나무 & Im 135410 & \\
\hline Rosa multiflora Thunb. & 찔레꽃 & IE 134883 & \\
\hline Rubus corchorifolius L. f. & 수리딸기 & IP 160301 & \\
\hline Rubus coreanus Miq. & 복분자딸기 & IP 160386 & \\
\hline Rubus crataegifolius Bunge & 산딸기 & IP 160246 & \\
\hline Rubus parvifolius $\mathrm{L}$. & 멍석딸기 & C 012126 & \\
\hline Rubus phoenicolasius Maxim. & 곰딸기 & IP 160558 & \\
\hline Sanguisorba officinalis L. & 오이풀 & C 012112 & \\
\hline
\end{tabular}


Appendix 1. Continued.

\begin{tabular}{|c|c|c|c|}
\hline Taxa & Korean name & Voucher number & Category \& Criteria \\
\hline Sorbus alnifolia (Siebold et Zucc.) C. Koch. & 팥배나무 & C 041600 & \\
\hline Spiraea prunifolia f. simpliciflora Nakai & 조팝나무 & Im 135428 & \\
\hline Stephanandra incisa Zabel & 국수나무 & IE 134880 & \\
\hline \multicolumn{4}{|l|}{ Leguminosae 콩과 } \\
\hline Aeschynomene indica $\mathrm{L}$. & 자귀풀 & Im 141223 & \\
\hline Albizzia julibrissin Duraz. & 자귀나무 & C 012165 & \\
\hline Amorpha fruticosa $\mathrm{L}$. & 족제비싸리 & C 012163 & $\mathrm{~N}$ \\
\hline Astragalus sinicus L. & 자운영 & C 012162 & $\mathrm{~N}$ \\
\hline Caragana sinica (Buchoz) Rehder & 골담초 & C 039005 & \\
\hline Desmodium oldhami Oliv. & 큰도둑놈의갈고리 & Im 140659 & \\
\hline $\begin{array}{l}\text { Desmodium podocarpum var. oxyphyllum (DC.) H. } \\
\text { Ohashi }\end{array}$ & 도둑놈의갈고리 & Im 105538 & \\
\hline Desmodium podocarpum DC. & 개도둑놈의갈고리 & C 012180 & \\
\hline Glycine soja Siebold et Zucc. & 돌콩 & C 012168 & \\
\hline Indigofera koreana Ohwi & 민땅비싸리 & IP 160253 & \\
\hline Indigofera pseudotinctoria Matsum. & 낭아초 & Im 135306 & III \\
\hline Kummerowia striata (Thunb.) Schindl & 매듭풀 & Im 135136 & \\
\hline Lathyrus davidii Hance & 활량나물 & C 012166 & \\
\hline Lespedeza bicolor Turcz. & 싸리 & $\operatorname{Im} 140510$ & \\
\hline Lespedeza cuneata G. Don & 비수리 & $\operatorname{Im} 140634$ & \\
\hline Lespedeza cyrtobotrya Miq. & 참싸리 & Im 140528 & \\
\hline Lespedeza maximowiczii C. K. Schneid. & 조록싸리 & IP 160253 & \\
\hline Lespedeza maximowiczii var. tomentella Nakai & 털조록싸리 & $\operatorname{Im} 135373$ & \\
\hline Lespedeza. thunbergii subsp. formosa (Vogel) H. Ohashi & 풀싸리 & $\operatorname{Im} 140643$ & \\
\hline Lotus corniculata var. japonica Regel & 벌노랑이 & C 012170 & \\
\hline Maackia amurensis Rupr. & 다릅나무 & $\operatorname{Im} 135311$ & \\
\hline Pueraria lobata (Wild) Ohwi & 칡 & Im 135304 & \\
\hline Robinia pseudoacacia L. & 아까시나무(재) & $\operatorname{Im} 100129$ & $\mathrm{~N}$ \\
\hline Sophora flavescens Aiton. & 고삼 & C 012195 & \\
\hline Trifolium pratense $\mathrm{L}$. & 붉은토끼풀 & C 038990 & $\mathrm{~N}$ \\
\hline Trifolium repens $\mathrm{L}$. & 토끼풀 & Im 090038 & $\mathrm{~N}$ \\
\hline Vicia amoena Fisch. ex DC. & 갈퀴나물 & C 012190 & \\
\hline Vicia angustifolia var. segetilis K. Koch. & 살갈퀴 & C 012189 & \\
\hline Vicia hirsuta (L.) Gray & 새완두 & C 012177 & \\
\hline Vicia hirticalycina Nakai & 나래완두 & $\operatorname{Im} 090126$ & $\mathrm{E}$ \\
\hline Vicia japonica A. Gray & 넓은잎갈퀴 & C 012186 & \\
\hline Vicia pseudorobus Fisch. et C. A. Mey & 큰등갈퀴 & C 012185 & I \\
\hline Vicia tetrasperma $($ L.) Schrb. & 얼치기완두 & $\operatorname{Im} 012184$ & \\
\hline Vicia unijuga A. Braun & 나비나물 & Im 012175 & \\
\hline Vicia venosa Maxim. & 연리갈퀴 & Im 038989 & \\
\hline
\end{tabular}


Appendix 1. Continued.

\begin{tabular}{|c|c|c|c|}
\hline Taxa & Korean name & Voucher number & Category \& Criteria \\
\hline Vigna angularis var. nipponensis (Ohwi) Ohwi et H. Ohashi & 새팥 & $\operatorname{Im} 105525$ & \\
\hline \multicolumn{4}{|l|}{ Elaeagnacea 보리수나무과 } \\
\hline Elaeagnus umbellata Thunb. & 보리수나무 & IP 160220 & \\
\hline \multicolumn{4}{|l|}{ Onagaceae 바늘꽃과 } \\
\hline Circaea mollis Siebold et Zucc. & 털이슬 & Im 140518 & \\
\hline Epilobium pyrricolophum Franch. et Sav. & 바늘꽃 & $\operatorname{Im} 100142$ & \\
\hline \multicolumn{4}{|l|}{ Alangiaceae 박쥐나무과 } \\
\hline Alangium platanifolium var. trilobum (Miq.) Ohwi. & 박쥐나무 & IP 160221 & \\
\hline \multicolumn{4}{|l|}{ Cornaceae 충충나무과 } \\
\hline Cornus controversa Hemsl & 층층나무 & Im 134877 & \\
\hline Cornus kousa F. Buerger ex Hance & 산딸나무 & IP 160578 & \\
\hline Cornus macrophylla Wall. & 곰의말채나무 & $\operatorname{Im} 140641$ & \\
\hline \multicolumn{4}{|l|}{ Santalaceae 단향과 } \\
\hline Thesium chinense Turcz. & 제비꿀 & IE 134848 & \\
\hline \multicolumn{4}{|l|}{ Celastraceae 노박덩굴과 } \\
\hline Celstrus orbiculatus Thunb. & 노박덩굴 & C 012158 & \\
\hline $\begin{array}{l}\text { Euonymus alatus f. ciliatodentatus (Franch et Sav.) } \\
\text { Hiyama }\end{array}$ & 회잎나무 & C 012153 & \\
\hline Euonymus oxyphyllus Miq. & 참회나무 & IP 160371 & \\
\hline Euonymus hamiltonianus Wall. & 참빗살나무 & $\operatorname{Im} 012075$ & \\
\hline Tripterygium regelii Sprague et Takeda & 미역줄나무 & $\operatorname{Im} 012151$ & \\
\hline \multicolumn{4}{|l|}{ Aquifoliaceae 감탕나무과 } \\
\hline Ilex macropoda Miq. & 대팻집나무 & C 012150 & \\
\hline \multicolumn{4}{|l|}{ Euphorbiaceae 대극과 } \\
\hline Euphorbia sieboldiana Morren et Decne & 개감수 & IP 90368 & \\
\hline Phyllanthus ussuriensis Rupr. et Maxim. & 여우주머니 & Im 140612 & \\
\hline Sapium japonicum Pax et Hoffm. & 사람주나무 & IE 134884 & \\
\hline Securiniega suffruticosa Rehder & 광대싸리 & Im 041586 & \\
\hline \multicolumn{4}{|l|}{ Rhamnanceae 갈매나무과 } \\
\hline Rhamnella frangulioides (Maxim.) Weberb. & 까마귀베개 & $\operatorname{Im} 140759$ & \\
\hline Rhamnus yoshinoi Makino & 짝자래나무 & $\operatorname{Im} 140758$ & \\
\hline \multicolumn{4}{|l|}{ Vitaceae 포도과 } \\
\hline Ampelopsis heterophylla (Thunb.) Siebold et Zucc. & 개머루 & C 050182 & \\
\hline Ampelopsis brevipedunculata f. ciliata (Nakai) T. B. Lee & 털개머루 & Im 140665 & \\
\hline Parthenoicssus tricuspidata (Siebold et Zucc.) Planch. & 담쟁이덩굴 & C 012263 & \\
\hline Vitis amurensis Rupr. & 왕머루 & IP 160207 & \\
\hline Vitis flexuosa Thunb. & 새머루 & IP 160237 & \\
\hline Vitis ficifolia var. sinuata (Regel) H. Hara & 까마귀머루 & C 012259 & \\
\hline \multicolumn{4}{|l|}{ Polygalaceae 원지과 } \\
\hline Polygala japonica Houtt. & 애기풀 & Im 012145 & \\
\hline
\end{tabular}


Appendix 1. Continued.

\begin{tabular}{|c|c|c|c|}
\hline Taxa & Korean name & Voucher number & Category \& Criteria \\
\hline Polygala sibirica $\mathrm{L}$. & 두메애기풀 & $\operatorname{Im} 041590$ & \\
\hline \multicolumn{4}{|l|}{ Staphyleaceae 고추나무과 } \\
\hline Staphylea bumalda DC. & 고추나무 & IP 160540 & \\
\hline \multicolumn{4}{|l|}{ Aceraceae 단풍나무과 } \\
\hline Acer poictum subsp. mono (Maxim.) Ohashi & 고로쇠나무 & Im 140805 & \\
\hline Acer pseudosieboldianum (Pax.) Kom. & 당단풍나무 & Im 012160 & \\
\hline Acer tataricum subsp. ginnala (Maxim.) Wesm. & 신나무 & IP 113681 & \\
\hline \multicolumn{4}{|l|}{ Anacardiaceae 옻나무과 } \\
\hline Rhus javanica $\mathrm{L}$. & 붉나무 & C 012148 & \\
\hline Rhus sylvestis Siebold et Zucc. & 산검양옻나무 & Im 012584 & \\
\hline Rhus trichocarpa Miq. & 개옻나무 & C 012147 & \\
\hline \multicolumn{4}{|l|}{ Simaroubaceae 소태나무과 } \\
\hline Picrasma quassioides (D.Don) Benn. & 소태나무 & Im 041572 & \\
\hline \multicolumn{4}{|l|}{ Rutaceae 운향과 } \\
\hline Evodia daniellii Hemsl. & 쉬나무 & C 134879 & \\
\hline Orixa japonica Thunb. & 상산 & C 041593 & I \\
\hline Zanthoxylum piperatum (L.) DC. & 초피나무 & C 012143 & \\
\hline Zanthoxylum schinifolium Siebold et Zucc. & 산초나무 & IP 134871 & \\
\hline Zanthoxylum schinifolium var. inermis T. B. Lee & 민산초나무 & C 012142 & \\
\hline \multicolumn{4}{|l|}{ Oxalidaceae 갱이밥과 } \\
\hline Oxalis corniculata $\mathrm{L}$. & 괭이밥 & C 012144 & \\
\hline Oxalis obtriangulata Maxim. & 큰괭이밥 & Im 100133 & I \\
\hline \multicolumn{4}{|l|}{ Geraniaceae 쥐손이풀과 } \\
\hline Geranium thunbergii Siebold et Zucc. & 이질풀 & Im 140611 & \\
\hline Geranium wilfordii Maxim. & 세잎쥐손이 & C 012197 & \\
\hline \multicolumn{4}{|l|}{ Balsaminaceae 봉선화과 } \\
\hline Impatiens textori Miq. & 물봉선 & IP 134871 & \\
\hline \multicolumn{4}{|l|}{ Araliaceae 두릅나무과 } \\
\hline Eleutherococcus sessiliflorus (Rupr. et Maxim.) S.Y. Hu & 오갈피나무 & Im 012235 & \\
\hline Aralia elata (Miq.) Seem. & 두릅나무 & Im 140454a, b & \\
\hline Kalopanax septemlobus (Thunb.) Koidz. & 음나무 & Im 135294 & \\
\hline \multicolumn{4}{|l|}{ Umbeliferae 산형과 } \\
\hline Angelica decursiva (Miq.) Franch. et Sav. & 바디나물 & Im 140703 & \\
\hline Angelica gigas Nakai & 참당귀 & C 012247 & \\
\hline Angelica grosseserratum (Maxim.) Kitag. & 신감채 & IP 80866 & \\
\hline Angelica polymorpha Maxim. & 궁궁이 & Im 140711 & \\
\hline Cryptotaenia japonica Hassk. & 파드득나물 & Im 135338 & \\
\hline Heracleum moellendorffii Hance & 어수리 & C 012246 & \\
\hline Hydrocotyle ramiflora Maxim. & 큰피막이 & C 039771 & \\
\hline Osmorhiza aristata (Thunb.) Makino \& Yabe & 긴사상자 & IP $160550 a, b$ & \\
\hline
\end{tabular}


Appendix 1. Continued.

\begin{tabular}{|c|c|c|c|}
\hline Taxa & Korean name & Voucher number & Category \& Criteria \\
\hline Pimpinella brachycarpa (Kom.) Nakai & 참나물 & C 012245 & \\
\hline Sanicula chinensis Bunge & 참반디 & IP 160334 & \\
\hline Sium suave Walter & 개발나물 & IC $134839 a, b$ & \\
\hline Torilis japonica (Houtt.) DC. & 사상자 & C 012242 & \\
\hline \multicolumn{4}{|l|}{ Gentianaceae 용담과 } \\
\hline Gentiana scabra Bunge & 용담 & Im 135320 & \\
\hline Gentiana zollingeri Faw. & 큰구슬붕이 & C 044771 & \\
\hline \multicolumn{4}{|l|}{ Asclepiadaceae 박주가리과 } \\
\hline Metaplexis japonica (Thunb.) Makino & 박주가리 & Im 135290 & \\
\hline \multicolumn{4}{|l|}{ Solanaceae 가지과 } \\
\hline Scopolia japonica Maxim. & 미치광이풀 & IP 135305 & III, LC \\
\hline Solanum carolinense L. & 도깨비가지 & Im 140686 & \\
\hline Solanum lyratum Thunb. & 배풍등 & Im 044881 & \\
\hline Solanum nigrum L. & 까마중 & Im 044883 & $\mathrm{~N}$ \\
\hline Physaliastrum japonicum (Franch. et Sav.) Honda & 가시꽈리 & Im 090121 & \\
\hline Physalis alkekengi var. franchetii (Mast) Makino & 꽈리(재) & C 012318 & \\
\hline \multicolumn{4}{|l|}{ Convolvulaceae 메꽃과 } \\
\hline Calystegia australis $\mathrm{R} . \mathrm{Br}$. & 실새삼 & Im 140924 & \\
\hline Calystegia sepium var. japonicum (Choisy) Makino & 메꽃 & C 012286 & \\
\hline Quamoclit coccinea Moench & 둥근잎유홍초 & Im 105539 & $\mathrm{~N}$ \\
\hline \multicolumn{4}{|l|}{ Borraginaceae 지치과 } \\
\hline Bothriospermum tenellum (Hornem.) Fisch. et C. A. Mey. & 꽃받이 & IP 140941 & \\
\hline Trigonotis radicans var. sericea (Maxim.) H. Hara & 참꽃마리 & IP 160231 & \\
\hline Trigonotis peduncularis (Trevir) Benth. ex Hemsl & 꽃마리 & Im 090048 & \\
\hline \multicolumn{4}{|l|}{ Verbenaceae 마편초과 } \\
\hline Callicarpa japonica Thunb. & 작살나무 & IP 160327 & \\
\hline Caryopteris divaricata (Siebold et Zucc.) Maxim. & 누린내풀 & IP 140894 & \\
\hline Clerodendron trichotomum Thunb. & 누리장나무 & Im 140489 & \\
\hline Vitex negundo var. cannabifolia Siebold et Zucc. & 목형(재) & C 012305 & \\
\hline \multicolumn{4}{|l|}{ Phrymaceae 파리풀과 } \\
\hline Phryma leptostachya var. asiatica Hara & 파리풀 & IP 160548 & \\
\hline \multicolumn{4}{|l|}{ Labiatae 꿀풀과 } \\
\hline Agastache rugosa (Fisch. et Meyer) Kuntze & 배초향 & Im 140764 & \\
\hline Ajuga decumbens Thunb. & 금창초 & IP 160224 & \\
\hline Ajuga spectabilis Nakai & 자란초 & IP 070498 & E,II \\
\hline Clinopodium chinense var. parviflorum (Kudo) H. Hara & 층층이꽃 & Im 140523 & \\
\hline Clinopodium gracile var. multicaule (Maxim.) Ohwi & 탑꽃 & Im 140653 & \\
\hline Clinopodium micranthum (Regel) Hara & 두메층층이 & Im 140506 & I \\
\hline Elsholtzia splendens Nakai ex F. Maek. & 꽃향유 & Im 135778 & \\
\hline Isodon inflexus (Thunb.) Kudo & 산박하 & Im 105540 & \\
\hline
\end{tabular}


Appendix 1. Continued.

\begin{tabular}{|c|c|c|c|}
\hline Taxa & Korean name & Voucher number & Category \& Criteria \\
\hline $\begin{array}{l}\text { Lamium album var. barbatum (Siebold et Zucc.) Franch. } \\
\text { et Sav. }\end{array}$ & 광대수염 & IC 985129 & \\
\hline Lamium amplexicaule $\mathrm{L}$. & 광대나물 & IP 160290 & \\
\hline Lamium purpureum L. & 자주광대나물 & Im 135329 & $\mathrm{~N}$ \\
\hline Leonurus japonicus Houtt. & 익모초 & C 012358 & \\
\hline Leonurus macranthus Maxim. & 송장풀 & Im 140568 & \\
\hline Lycopus lucidus Turcz.ex Benth & 쉽싸리 & Im 140502 & \\
\hline Meehania urticifolia (Miq.) Makino & 벌깨덩굴 & IP 160232 & \\
\hline Mosla dianthera Maxim. & 쥐깨풀 & Im 039551 & \\
\hline Mosla punctulata (J.F. Gmelin) Nakai & 들깨풀 & IP 81714 & \\
\hline Phlomis umbrosa Turcz. & 속단 & Im 140558 & \\
\hline Prunella vulgaris var. lilacina Nakai & 꿀풀 & IP 135357 & \\
\hline Salvia plebeia $\mathrm{R} . \mathrm{Br}$. & 배암차즈기 & C 3043 & \\
\hline Scutellaria dentata var. alpina Nakai & 수골무꽃 & Im 160449 & \\
\hline Scutellaria indica $\mathrm{L}$. & 골무꽃 & Im 135774 & \\
\hline Scutellaria insignis Nakai & 광릉골무꽃 & IP 160581 & E, III, LC \\
\hline Scutellaria pekinensis var. transitra Hara & 산골무꽃 & C 012369 & \\
\hline Scutellaria pekinensis var. ussuriensis (Regel) Hand.-Maz. & 호골무꽃 & $\operatorname{Im} 134801$ & \\
\hline Stachys japonica Miq. & 석잠풀 & C 012371 & \\
\hline \multicolumn{4}{|l|}{ Plantaginaceae 질경이과 } \\
\hline Plantago asiatica $\mathrm{L}$. & 질경이 & Im 090053 & \\
\hline \multicolumn{4}{|l|}{ Oleaceae 물푸레나무과 } \\
\hline Chionanthus retusus Lindl. \& Paxton & 이팝나무 & IP 134870 & II, LC \\
\hline Fraxinus rhynchophylla Hance & 물푸레나무 & C 012272 & \\
\hline Fraxinus sieboldiana Blume & 쇠물푸레나무 & IP 160203 & \\
\hline Ligustrum japonicum Thunb. & 광나무(재) & C 012271 & I \\
\hline Ligustrum obtusifolium Siebold et Zucc. & 쥐똥나무 & C 012296 & \\
\hline \multicolumn{4}{|l|}{ Scrophulariaceae 현삼과 } \\
\hline Mazus pumilus (Burm. f.) Van Steenis & 주름잎 & C 044884 & \\
\hline Melampyrum roseum Maxim. & 꽃며느리밥풀 & Im 140472 & \\
\hline Pedicularis resupinata $\mathrm{L}$. & 송이풀 & C 012310 & \\
\hline Phtheirospermum japonicum (Thunb.) Kanitz & 나도송이풀 & Im 135305 & \\
\hline Scrophularia kakudensis Franch. & 큰개현삼 & Im 044889 & \\
\hline Veronica arvensis $\mathrm{L}$. & 선개불알풀 & Im 090046 & $\mathrm{~N}$ \\
\hline Veronica hederaefolia $\mathrm{L}$. & 눈개불알풀 & CK 135294 & $\mathrm{~N}$ \\
\hline Veronica persica Poir. & 큰개불알풀 & C 012309 & $\mathrm{~N}$ \\
\hline Veronica didyma var. lilacina (H. Hara) T. Yamaz. & 개불알풀 & C 044995 & \\
\hline \multicolumn{4}{|l|}{ Acanthaceae 쥐꼬리망초과 } \\
\hline Justicia procumbens L. & 쥐꼬리망초 & Im 012320 & \\
\hline Campanulaceae 초롱꽃과 & & & \\
\hline
\end{tabular}


Appendix 1. Continued.

\begin{tabular}{|c|c|c|c|}
\hline Taxa & Korean name & Voucher number & Category \& Criteria \\
\hline Adenophora divaricata Franch. \& Sav. & 넓은잔대 & K.S.H. 2883 & \\
\hline Adenophora polyantha Nakai & 수원잔대 & K.Y.K. 2882 & \\
\hline Adenophora remotiflora (Siebold et Zucc.) Miq. & 모시대 & Im 045118 & \\
\hline Adenophora stricta Miq. & 당잔대 & Im 140375 & \\
\hline Adenophora triphylla var. japonica Hara & 잔대 & C 019697 & \\
\hline Asyneuma japonicum (Miq.) Briq. & 영아자 & Im 044778 & \\
\hline Codonopsis lanceolata (Siebold et Zucc.) Trautv. & 더덕 & C 012344 & \\
\hline Platycodon grandiflorum (Jacq.) A. DC & 도라지 & Im 044777 & \\
\hline Platycodon grandiflorum f. albiflorum (Honda) H. Hara & 백도라지 & C 012351 & \\
\hline \multicolumn{4}{|l|}{ Rubiaceae 꼭두서니과 } \\
\hline Asperula maximowiczii Kom. & 개갈퀴 & IP 134803 & \\
\hline Galium dahuricum Turc ex. Ledeb. & 큰잎갈퀴 & Im 141443 & \\
\hline Galium gracilens (A. Gray) Makino & 좀네잎갈퀴 & Im 141442 & \\
\hline Galium pogonanthum Franch. et Sav. & 산갈퀴 & Im 160504 & \\
\hline Galium spurium var. echinospermon (Wallr.) Hayek & 갈퀴덩굴 & C 012405 & \\
\hline Galium trachyspermum A. Gray & 네잎갈퀴 & IP 134774 & \\
\hline Galium verum var. asiaticum Nakai & 솔나물 & Im 141382 & \\
\hline Paederia scandens (Lour.) Merr. & 계요등 & Im 140507 & \\
\hline Rubia akane Nakai & 꼭두서니 & Im 141337 & \\
\hline Rubia chinensis Regel \& Maak & 큰꼭두서니 & IP 160552 & \\
\hline Rubia cordifolia var. pratensis Maxim. & 갈퀴꼭두서니 & C 012321 & \\
\hline \multicolumn{4}{|l|}{ Diervillaceae 병꽃나무과 } \\
\hline Weigela subsessilis (Nakai) L.H. Bailey & 병꽃나무 & Im 141333 & E \\
\hline \multicolumn{4}{|l|}{ Caprifoliaceae 인동과 } \\
\hline Lonicera harae Makino & 길마가지나무 & IP 122276 & \\
\hline Lonicera japonica Thunb. & 인동덩굴 & Im 140833 & \\
\hline Lonicera praeflorens Batalin & 올괴불나무 & IP 60405 & I \\
\hline \multicolumn{4}{|l|}{ Viburnaceae 산분꽃나무과 } \\
\hline Viburnum dilatatum Thunb. & 가막살나무 & IP 134885 & \\
\hline Viburnum erosum Thunb. & 덜뀡나무 & IP 135366 & \\
\hline \multicolumn{4}{|l|}{ Adoxaceae 연복초과 } \\
\hline Sambucus williamsii var. coreana (Nakai) Nakai & 딱총나무 & IP 160288 & \\
\hline \multicolumn{4}{|l|}{ Valerianaceae 마타리과 } \\
\hline Patrinia saniculaefolia Hemsl. & 금마타리 & Im 140583 & II, LC \\
\hline Patrinia scabiosaefolia ex Trevir. & 마타리 & IP 135452 & \\
\hline Patrinia villosa (Thunb.) Juss. & 뚝갈 & Im 045110 & \\
\hline Valeriana fauriei Briq. & 쥐오줌풀 & C 012340 & \\
\hline \multicolumn{4}{|l|}{ Compositae 국화과 } \\
\hline Achillea alpina $\mathrm{L}$. & 톱풀 & C 012413 & II \\
\hline Adenocaulon himalaicum Edgew. & 멸가치 & C 012415 & \\
\hline
\end{tabular}


Appendix 1. Continued.

\begin{tabular}{|c|c|c|c|}
\hline Taxa & Korean name & Voucher number & Category \& Criteria \\
\hline Ainsliaea acerifolia Sch.-Bip. & 단풍취 & IE 134847 & \\
\hline Ambrosia artemisiifolia $\mathrm{L}$. & 돼지풀 & C 012422 & $\mathrm{~N}$ \\
\hline Artemisia japonica Thunb. & 제비쑥 & C 012465 & \\
\hline Artemisia keiskeana Miq. & 맑은대쑥 & Im 140559 & \\
\hline Artemisia princeps Pamp. & 丛 & $\operatorname{Im} 81405$ & \\
\hline Artemisia stolonifera (Maxim.) Kom. & 넓은잎외잎쑥 & $\operatorname{Im} 140597$ & \\
\hline Artemisia sylvatica Maxim. & 그늘쑥 & $\operatorname{Im} 140520$ & \\
\hline Aster ageratoides Turcz. & 까실쑥부쟁이 & IP 80868 & \\
\hline Aster koraiensis Nakai & 벌개미취 & $\operatorname{Im} 140602$ & $\mathrm{E}$ \\
\hline Aster meyendorfii (Regel \& Maack) Voss & 개쑥부쟁이 & IP 134881 & \\
\hline Aster pinnatifidus (Maxim.) Kitam. & 버드쟁이나물 & C 012471 & \\
\hline Aster scaber Thunb. & 참취 & $\operatorname{Im} 012410$ & \\
\hline Atractylodes ovata (Thunb.) DC. & 삽주 & $\operatorname{Im~140369a,~b~}$ & \\
\hline Bellis perennis $\mathrm{L}$. & 데이지(재) & $\operatorname{Im} 135902$ & \\
\hline Bidens biternata (Lour.) Merr. et Sherff ex Sherff & 털도깨비바늘 & Im 140761 & \\
\hline Carpesium abrotanoides $\mathrm{L}$. & 담배풀 & $\operatorname{Im~} 140525 \mathrm{a}, \mathrm{b}, \mathrm{c}$ & \\
\hline Carpesium cernuum $\mathrm{L}$. & 좀담배풀 & C 012429 & \\
\hline Centipeda minima (L.) A.Br. et Asch. & 중대가리풀 & IP 135324 & \\
\hline Chrysanthemum leucanthemum $\mathrm{L}$. & 불란서국화 & $\operatorname{Im} 90102$ & $\mathrm{~N}$ \\
\hline $\begin{array}{l}\text { Chrysanthemum zawadskii subsp. latilobum (Maxim.) } \\
\text { Kitag. }\end{array}$ & 구절초 & IP 134880 & \\
\hline Cirsium japonicum var. maackii (Maxim.) Matsum & 엉겅퀴 & IP 135300 & \\
\hline Cirsium setidens (Dunn) Nakai & 고려엉겅퀴 & Im 140462a, b & E, II \\
\hline Conyza canadensis (L.) Cronquist & 망초 & $\operatorname{Im} 140500$ & $\mathrm{~N}$ \\
\hline Coreopsis tinctoria Nutt. & 기생초 & Im 113987 & $\mathrm{~N}$ \\
\hline Crassocephalum crepidioides (Benth.) S. Moore & 주홍서나물 & Im 140449 & $\mathrm{~N}$ \\
\hline Crepidiastrum chelidoniifolium (Makino) Pak et Kawano & 까치고들빼기 & Im 140443 & \\
\hline Crepidiastrum denticulatum (Houtt.) Pak et Kawano & 이고들빼기 & $\operatorname{Im} 81401$ & \\
\hline Crepidiastrum sonchifolium (Maxim.) Pak et Kawano & 고들빼기 & Im 090101 & \\
\hline Dendranthema boreale (Makino) Ling ex Kitam. & 산국 & Im 140705 & \\
\hline Dendranthema zawadskii var. latilobum (Maxim.) Kitam. & 구절초 & Im 140431 & \\
\hline Echinops setifer Iljin & 절굿대 & $\operatorname{Im} 012401$ & \\
\hline Erechtites hieracifolia Raf. & 붉은서나물 & C 012402 & $\mathrm{~N}$ \\
\hline Erigeron annuus (L.) Pers. & 개망초 & $\operatorname{Im} 2962$ & $\mathrm{~N}$ \\
\hline Eupatorium japonicum Thunb. & 등골나물 & $\operatorname{Im} 140500$ & \\
\hline Eupatorium lindleyanum DC. & 골등골나물 & $\operatorname{Im} 140579$ & \\
\hline Gnaphalium affine D. Don & 떡쑥 & Im 090301 & \\
\hline Galinsoga ciliate (Raf.) S. F. Blake & 털별꽃아재비 & $\operatorname{Im} 135303$ & $\mathrm{~N}$ \\
\hline Helianthus tuberosus L. & 뚱딴지 & Im 100139 & \\
\hline Hemistepa lyrata Bunge & 지칭개 & C 012390 & \\
\hline
\end{tabular}


Appendix 1. Continued.

\begin{tabular}{|c|c|c|c|}
\hline Taxa & Korean name & Voucher number & Category \& Criteria \\
\hline Hieracium umbellatum $\mathrm{L}$. & 조밥나물 & C 012391 & \\
\hline Inula britannica var. linariaefolia Regel & 가는금불초 & C 140479 & \\
\hline Ixeridium dentatum (Thunb.) Tzvelev & 씀바귀 & IP 135356 & \\
\hline Ixeridium dentatum f.albiflora (Makino) H. Hara & 흰씀바귀 & Im 140824 & \\
\hline Ixeris chinensis (Thunb.) Nakai & 노랑선씀바귀 & C 012394 & \\
\hline Ixeris debilis (Thunb.) A.Gray & 벋음씀바귀 & C 140471 & \\
\hline Ixeris polycephala Cass. & 벌씀바귀 & Im 090305 & \\
\hline Ixeris strigosa (H. Lev. et Vaniot) J. H. Pak et Kawano & 선씀바귀 & Im 135364 & \\
\hline Lactuca indica $\mathrm{L}$. & 왕고들빼기 & Im 081402 & \\
\hline Lactuca raddeana Maxim. & 산씀바귀 & Im 140585 & \\
\hline Lapsana apogonoides (Maxim.) J. H. Pak \& Bremer & 개보리뺑이 & Im 140469 & \\
\hline Leibnitzia anandria (L.) Turcz. & 솜나물 & C 012449 & \\
\hline Ligularia fischeri (Ledeb.) Turcz. & 곰취 & Im 140463 & II \\
\hline Petasites japonicus (Siebold et Zucc.) Maxim. & 머위 & Im 140460 & \\
\hline Picris hieracioides var. koreana Kitam & 쇠서나물 & Im 135321 & \\
\hline Rudbeckia bicolor Nutt. & 원추천인국 & Im 140713 & \\
\hline Saussurea gracilis Maxim. & 은분취 & Im 140457 & \\
\hline Saussurea grandifolia Maxim. & 서덜취 & Im 140473 & \\
\hline Saussurea maximowiczii Herd & 버들분취 & Im $105517 a, b$ & \\
\hline Senecio vulgaris $\mathrm{L}$. & 개쑥갓 & C $140-50$ & $\mathrm{~N}$ \\
\hline Serratula coronata var. insularis Kitamura & 산비장이 & C 012384 & \\
\hline Sigesbeckia glabrescens (Makino) Makino & 진득찰 & IP 80855 & \\
\hline Solidago serotina Aiton. & 미국미역취 & C 2940 & $\mathrm{~N}$ \\
\hline Solidago virgaurea subsp. asiatica Kitam.ex H. Hara & 미역취 & IP 134884 & \\
\hline Sonchus asper (L.) Hill & 큰방가지똥 & C 012463 & $\mathrm{~N}$ \\
\hline Sonchus oleraceus L. & 방가지똥 & C 012464 & $\mathrm{~N}$ \\
\hline Syneilesis palmata (Thunb.) Maxim. & 우산나물 & Im 012443-2 & \\
\hline Synurus excelsus (Makino) Kitam. & 큰수리취 & $\operatorname{Im} 012461$ & \\
\hline Taraxacum coreanum Nakai & 흰민들레 & Im 140446 & \\
\hline Taraxacum officinale Weber & 서양민들레 & C 012460 & $\mathrm{~N}$ \\
\hline Taraxacum platycarpum Dahlst. & 민들레 & Im 100153 & \\
\hline Tephroseris kirilowill (Turcz. ex DC.) Holub & 솜방망이 & C 012383 & \\
\hline Youngia chelidoniifolia (Makino) Pak et Kawano & 까치고들빼기 & IE 134846 & \\
\hline Youngia japonica (L.) DC. & 뽀리뱅이 & Im 090307 & \\
\hline \multicolumn{4}{|l|}{ Araceae 천남성과 } \\
\hline Arisaema amurense Maxim. & 둥근잎천남성 & Im 135307 & \\
\hline Arisaema heterophyllum Blume & 두루미천남성 & IP 113649 & II, LC \\
\hline Arisaema peninsulae Nakai & 점박이천남성 & IP 105541 & \\
\hline \multicolumn{4}{|l|}{ Commelinaceae 닭의장풀과 } \\
\hline Commelina communis L. & 닭의장풀 & IP 160228 & \\
\hline
\end{tabular}


Appendix 1. Continued.

\begin{tabular}{|c|c|c|c|}
\hline Taxa & Korean name & Voucher number & Category \& Criteria \\
\hline Tradescantia refelxa Raf. & 자주닭개비 & C 012536 & \\
\hline \multicolumn{4}{|l|}{ Juncaceae 골풀과 } \\
\hline Luzula capitata (Miq. ex Franch. \& Sav.) Kom & 꿩의밥 & Im 090312 & \\
\hline Juncus effusus var. decipiens Buchenau. & 골풀 & C 012542 & \\
\hline Juncus wallichianus J. Gay ex Laharpe & 눈비녀골풀 & IP 134873 & \\
\hline \multicolumn{4}{|l|}{ Cyperaceae 사초과 } \\
\hline Carex bostrychostigma Maxim. & 길뚝사초 & IP 160236 & \\
\hline Carex breviculmis $\mathrm{R} . \mathrm{Br}$. & 청사초 & IP 160226 & \\
\hline Carex ciliatomarginata Nakai & 털대사초 & IP 160222 & \\
\hline Carex dispalata Boott & 삿갓사초 & Im 140790 & \\
\hline Carex forficula Franch. \& Sav. & 산뚝사초 & IP 160298 & \\
\hline Carex gibba Wahlenb. & 나도별사초 & Im 160489 & \\
\hline Carex gifuensis Franch. & 애기감둥사초 & IP 160256 & III \\
\hline Carex humilis var. nana (H. Lev. et Vaniot) Ohwi & 가는잎그늘사초 & C 012505 & \\
\hline Carex japonica Thunb. & 개찌버리사초 & IP 160242 & \\
\hline Carex laevissima Nakai & 애괭이사초 & $\operatorname{Im} 21600$ & \\
\hline Carex lanceolata Boott & 그늘사초 & IP 122300 & \\
\hline Carex leiorhyncha C. A. Meyer & 산괭이사초 & IP 135358 & \\
\hline Carex lenta D. Don & 줄사초 & Im 105528 & \\
\hline Carex ligulata Nees & 갈사초 & IP 160332 & IV, DD, NE \\
\hline Carex maximowiczii Miq. & 왕비늘사초 & IP 122309 & \\
\hline Carex mitrata var. aristata Ohwi & 겨락겨사초 & IP 122303 & \\
\hline Carex mollicula Boott & 애기흰사초 & Im 090311 & \\
\hline Carex nervata Franch. et Sav. & 양지사초 & Im 142136 & I \\
\hline Carex okamotoi Ohwi & 지리대사초 & Im 090128 & E, II \\
\hline Carex parciflora var. macroglossa (Franch. et Sav.) Ohwi & 애기염주사초 & IP 122587 & \\
\hline Carex pediformis C. A. May & 넓은잎그늘사초 & Im 090335 & II \\
\hline Carex polyschoena $\mathrm{H}$. Lev. et Vaniot & 가지청사초 & IP 122308 & \\
\hline Carex sabynensis Less. ex Kunth & 실청사초 & Im 090303 & \\
\hline Carex siderosticta Hance & 대사초 & IP 160208 & \\
\hline Cyperus amuricus Maxim. & 방동사니 & Im 100131 & \\
\hline Cyperus globosus All. & 드렁방동사니 & IP 134888 & \\
\hline Cyperus iria $\mathrm{L}$. & 참방동사니 & Im 140615 & \\
\hline Cyperus microiria Steud. & 금방동사니 & Im 135303 & \\
\hline Eleocharis equisetiformis (Meinsh.) B. Fedtsch. & 까락골 & C 012441 & \\
\hline Scirpus karuizawensis Makino & 솔방울고랭이 & Im 140229 & \\
\hline Scirpus triangulatus Roxb. & 송이고랭이 & Im 140709 & \\
\hline $\begin{array}{l}\text { Scirpus wichurai var. asiaticus (Beetle) T. Koyama ex } \\
\text { Ohwi }\end{array}$ & 방울고랭이 & IP 134872 & \\
\hline Graminae 벼 과 & & & \\
\hline
\end{tabular}


Appendix 1. Continued.

\begin{tabular}{|c|c|c|c|}
\hline Taxa & Korean name & Voucher number & Category \& Criteria \\
\hline Agropyron tsukushiense var. transiens (Hack.) Ohwi & 개밀 & C 012556 & \\
\hline Agrostis clavata var. nukabo Ohwi & 겨이삭 & IP 160240 & \\
\hline Alopecurus aequalis Sobol & 뚝새풀 & Im 81131 & \\
\hline Alopecurus pratensis $\mathrm{L}$. & 큰뚝새풀 & C 012439 & \\
\hline Arundinella hirta (Thunb.)Tanaka & 새 & Im 039040 & \\
\hline Bromus tectorum $\mathrm{L}$. & 털빕새귀리 & C 039037 & $\mathrm{~N}$ \\
\hline Calamagrostis arundinacea (L.) Roth & 실새풀 & Im 105530 & \\
\hline Calamagrostis epigeios (L.) Roth & 산조풀 & C 012550 & \\
\hline Cymbopogon tartilis var. goeringii (Steud.) Hand.-Maz. & 개솔새 & C 012549 & \\
\hline Dactylis glomerata $\mathrm{L}$. & 오리새 & C 012548 & $\mathrm{~N}$ \\
\hline Diarrhena fauriei (Hack.) Ohwi & 광릉용수염 & $\operatorname{Im} 135290$ & \\
\hline Digitaria violascens Link & 민바랭이 & Im 140447 & \\
\hline Echinochloa crusgalli (L.) P. Beauv. & 돌피 & C 012546 & \\
\hline Echinochloa crusgalli var. oryzicola (Vasinger) Ohwi & 물피 & Im 140452 & \\
\hline Eleusine indica (L.) Gaertn. & 왕바랭이 & $\operatorname{Im} 444$ & \\
\hline Eragrostis ferruginea (Thunb.) P. Beauv. & 그령 & C 012564 & \\
\hline Eriochloa villosa (Thunb.) Kunth & 나도개피 & $\operatorname{Im} 140445$ & \\
\hline Festuca ovina $\mathrm{L}$. & 김의털 & C 140511 & \\
\hline Festuca parvigluma Steud. & 김의털아재비 & IP 160511 & \\
\hline Hierochloe odorata (L.) Beauv. & 향모 & C 039094 & \\
\hline Isachne globosa (Thunb.) Kuntze & 기장대풀 & C 012560 & \\
\hline Leersia japonica (Honda) Honda & 나도겨풀 & C 039092 & \\
\hline Lolium multiflorum Lam. & 쥐보리 & C 039089 & $\mathrm{~N}$ \\
\hline Lolium perenne $\mathrm{L}$. & 호밀풀 & $\mathrm{C} 012557$ & $\mathrm{~N}$ \\
\hline Melica onoei Franch. et Sav. & 쌀새 & Im 140767 & \\
\hline Microstegium vimineum (Trin.) A. Camus & 나도바랭이새 & Im 140453 & \\
\hline Milium effusum L. & 나도겨이삭 & IP 160376 & \\
\hline Miscanthus sinensis Andersson & 참억새 & C 012578 & \\
\hline Molinia japonica Hack. & 진퍼리새 & Im 039109 & \\
\hline Muhlenbergia huegelii Trin & 큰쥐꼬리새 & Im 039107 & \\
\hline Oplismenus undulatifolius (Ard.) P.Beauv. & 주름조개풀 & Im 105536 & \\
\hline Panicum bisulcatum Thunb. & 개기장 & IP 134875 & \\
\hline Paspalum thunbergii Kunth ex Steud. & 참새피 & $\operatorname{Im} 140601$ & \\
\hline Phragmites japonica Steud. & 달뿌리풀 & Im 135315 & \\
\hline Poa acroleuca Steud. & 실포아풀 & C 039100 & \\
\hline Pоа аппиа $\mathrm{L}$. & 새포아풀 & $\operatorname{Im} 81137$ & \\
\hline Poa nipponica Koidz. & 큰꾸러미풀 & IP 160234 & \\
\hline Sasa borealis (Hack.) Makino & 조릿대 & C 012568 & \\
\hline Setaria glauca (L.) P. Beauv. & 금강아지풀 & Im 135304 & \\
\hline Setaria viridis (L.) P. Beauv. & 강아지풀 & $\operatorname{Im} 135290$ & \\
\hline
\end{tabular}


Appendix 1. Continued.

\begin{tabular}{|c|c|c|c|}
\hline Taxa & Korean name & Voucher number & Category \& Criteria \\
\hline Spodiopogon cotulifer (Thunb.) Hack. & 기름새 & IP 80832 & \\
\hline Spodiopogon sibiricus Trin. & 큰기름새 & Im 140587 & \\
\hline Themeda triandra var. japonica Makino & 솔새 & C 012565 & \\
\hline Trisetum bifidum (Thunb.) Ohwi & 잠자리피 & IP 160395 & \\
\hline \multicolumn{4}{|l|}{ Typhaceae 부들과 } \\
\hline Typha angustifolia $\mathrm{L}$. & 애기부들 & C 039070 & \\
\hline \multicolumn{4}{|l|}{ Liliaceae 백합과 } \\
\hline Allium macrostemon Bunge & 산달래 & Im 090059 & \\
\hline Allium sacculiferum Maxim. & 참산부추 & IP 134882 & \\
\hline Asparagus scoberioides Kunth & 비짜루 & IP 160274 & \\
\hline Convallaria keiskei Miq. & 은방울꽃 & C 134826 & \\
\hline Disporum smilacinum A. Gray & 애기나리 & Im 141008 & \\
\hline Disporum uniflorum Baker & 윤판나물 & C $134828 a, b$ & \\
\hline Erythronium japonicum (Balrer) Decne. & 얼레지 & $\operatorname{Im} 090334$ & I \\
\hline Hemerocallis fulva (L.) L. & 원추리 & $\operatorname{Im} 140582$ & \\
\hline Hemerocallis minor Mill. & 애기원추리 & C 140492 & \\
\hline Hemerocallis thunbergii Baker. & 노랑원추리 & Im 140490 & \\
\hline Hosta capitata (Koidz.) Nakai & 일월비비추 & IP 135334 & I \\
\hline Lilium amabile Palibin & 털중나리 & IP 160568 & \\
\hline Lilium lancifolium Thunb. & 참나리 & C 140499 & \\
\hline Lilium tsingtauense Gilg & 하늘말나리 & IE 134831 & \\
\hline Liriope spicata (Thunb.) Lour. & 개맥문동 & Im 140646 & \\
\hline Paris verticillata $\mathrm{M}$. Bieb. & 삿갓나물 & IP 160429 & \\
\hline Polygonatum humile Fisch. ex Maxim. & 각시둥굴레 & Im 985103 & \\
\hline Polygonatum inflatum Kom. & 퉁둥굴레 & IP 160428 & \\
\hline Polygonatum involucratum (Franch. et Sav.) Maxim & 용둥굴레 & Im 140511 & \\
\hline Polygonatum lasianthum Maxim. & 죽대 & IE 134830 & \\
\hline Polygonatum odoratum var. pluriflorum Ohwi & 둥굴레 & IE 134851 & \\
\hline Scilla scilloides (Lind.) Druce & 무릇 & $\operatorname{Im} 40484$ & \\
\hline Smilacina japonica A. Gray & 풀솜대 & C 134835 & \\
\hline Smilax china $\mathrm{L}$. & 청미래덩굴 & $\operatorname{Im} 011920$ & \\
\hline $\begin{array}{l}\text { Smilax riparia var. ussuriensis (Regel) Hara et } \mathrm{T} \text {. } \\
\text { Koyama }\end{array}$ & 밀나물 & Im 012005 & \\
\hline Smilax sieboldii Miq. & 청가시덩굴 & Im 011919 & \\
\hline Tricyrtis macropoda Miq. & 뻐꾹나리 & IP 135455 & $\mathrm{LC}$ \\
\hline Tulipa edulis (Miq.) Baker & 산자고 & Im 140541 & \\
\hline Veratrum maackii var.parviflorum (Maxim.) Hara & 파란여로 & Im 011931 & \\
\hline \multicolumn{4}{|l|}{ Iridaceae 붓꽃과 } \\
\hline Iris ensata var. spontanea (Makino) Nakai & 꽃창포 & Im 140222 & II, LC \\
\hline Iris rossii Baker. & 각시붓꽃 & Im 135404 & \\
\hline
\end{tabular}


Appendix 1. Continued.

\begin{tabular}{|c|c|c|c|}
\hline Taxa & Korean name & Voucher number & Category \& Criteria \\
\hline \multicolumn{4}{|l|}{ Dioscoreaceae 마과 } \\
\hline Dioscorea batatas Decne. & 마 & $\operatorname{Im} 135772$ & \\
\hline Dioscorea nipponica Makino & 부채마 & Im 135302 & \\
\hline Dioscorea tenuipes Franch. et Sav. & 각시마 & C 011943 & \\
\hline \multicolumn{4}{|l|}{ Orchidaceae 난과 } \\
\hline Cephalanthera erecta (Thunb.) Blume & 은난초 & C 140116 & \\
\hline Cephalanthera falcata (Thunb.) Blume & 금난초 & Im 135279 & II \\
\hline Cephalanthera longibracteata Blume & 은대난초 & IP 81130 & \\
\hline Cremastra variabilis (Blume) Nakai ex Shibata & 약난초 & Im 135285 & III, VU, NT \\
\hline Cymbidium goeringii (Rchb. f.) Rchb. f. & 보춘화 & C 134536 & $\mathrm{LC}$ \\
\hline Habenaria linearifolia Maxim. & 잠자리난초 & Im 140114 & \\
\hline Liparis kumokiri F. Maek. & 옥잠난초 & C 012006 & \\
\hline Spiranthes sinensis (Pers.) Ames & 타래난초 & C 011937 & \\
\hline
\end{tabular}

Im, Hyoung-Tak Im; C, Jeong-Chae Jeong; IP, Hyoung-Tak Im and Su-Young Park; IE, Hyoung-Tak Im et al.

E, Endemic; I V, Specially designated plants of Ministry of Environment; EN, Endangered species; DD, Data Deficient; VU, Vulnerable; LC, Least Concern; NT, Near Threatened; NE, Not Evaluated; N, Invasive species designated by Ministry of Environment 